\section{A STUDY OF PSITTACOSIS.}

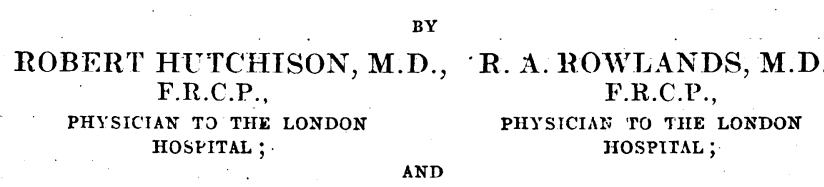

\section{S. LEVY SIMPSON, M.D., M.R.C.P.,}

MEDICAL FIRST ASSISTANT TO THE HOSPITAL.

WE describe below 27 cases of psittacosis that have come to our notice during the last few months. Of this number, 18 occurred in the London area, and the parrots associated with the remaining 9 cases were purchased from birdshops in London. The majority of the cases have been seen by one or other of us, and several have been observed throughout the greater part of their illness in the wards of the London Hospital. Of the 27 patients 5 died. Three of these deaths, however, occurred in one virulent family epidemic, involving five people.

Prior to the present epidemic of 1929-30 psittacosis was almost unknown in this country except for a few sporadic cases. It has, however, been recognized as a disease, and the association with parrots noted, for fifty years. Its rarity in recent times has tended to cause it to be forgotten, and this fact, coupled with an uncervain bacteriology, resulted in a sceptical attitude in the diagnosis of the case that occurred early in the recent epidemic. In fact, many of these were not unnaturally thought to be atypical typhoid, or influenzal pneumonia, and it was only through a letter inserted by one of us in the medical press that many of the cases came to our knowledgc.

The history of psittacosis constitutes an instructive epidemiological study, and has helped in the appreciation of many features of the present epidemic.

\section{Epidemiologr.}

In 1880 Ritter $^{1}$ described a small epidemic in Ulster, Switzerland. Seven persons were affected, of whom four lived in the house, one came daily, and the remaining two came to clean or repair bird-cages. The owner of the house was a bird collector, and parrots and other exotic birds had arrived a few weeks previously from Hamburg, and also from Vienna. Some of the birls died, and the remainder. were killed as suspect. Three of the seven patients died.

Small outbreaks were observed by Ost ${ }^{2}$ in Berne (1882), and Wagner ${ }^{3}$ in Leipzig (1882 and 1885). The Leipzis outbreaks are of great interest, for although some of the cases were caused by sick parrots, three cases in one household were apparently due to a sick dog bought from the parrot shop. The dog died.

The first extensive outbreak occurred in Paris in 1891-\&2. There were 50 cases, with 16 deaths in the first year. Smaller outbreaks occurred in the next few years. The Paris epidemic was investigated by several workers: Dujardin-Beaumetz, ${ }^{4}$ Dubief, ${ }^{4}$ Nocard, ${ }^{4}$ Sicard, ${ }^{5}$ Gilbert and Fournier, ${ }^{6}{ }^{78}$ etc. M. Dujardin-Beaumetz ${ }^{4}$ made the first report to the Council of Hygiene. Two Frenchmen, Dubois and Marion, brought a consignment of parrots from Buenos Aires to Havre. Of 500 birds, 300 died on the voyage. The two men fell ill, and the surviving parrots were distributed. All the subsequent cases except three could be definitely traced to contact with this batch of parrots. It is a matter of historical interest, however, that Dujardin-Beaumetz, in his first report, suggested that this was merely coincidence, and that they were dealing with an epidemic of influenza, and not a new illness inported into the country by parrots. In January, 1893, Dubief described two small epidemics originating from such parrots in different quarters of Paris, and Dujardin-Beaumetz was so impressed by the evidence that he asked leave to withdraw his original opinion, and to state, "I think, on the contrary, that the return of these epidemics and their identical course permit me to affirm that there is a relation of cause and effect.".
One of the house epidemics studied by Dr. Dubief is sufficiently iuteresting to report. It bcas a close resembiance to one of the London house epitemics studied by us.

"At 31 de la rue de Vaugirard there exisis a family pension kept by $M$. and Mmo M. On Jauuary 31st Mrme M. is taken ill with severe typhoid-like symptems. On February 8th there occurred a very intense pulmonary congestion, and after having been through a very bad poriod she is to-day completely cured. But her husband, aged 62, falls ill on February 2nd with signs of infection; he is seized with pneumonia on the 8th, and dies on February 9 th in the evening. The maid falls ill on February 2nd, and after having shown critical symptoms she recovers. The seamstress, aged 55, who worked in the apartment, is taken ill with signs of influenza on February 1st and dies with symptoms of pneumonia four days later. Finally, the porter of the house, aged 61 , is taken ill on February 4th; he presents symptoms of prostration and depression, and in spite of a slight improvement on February 15th he dies on the 20th with symptoms of pneumonia. Thus, of 5 persons attacked, 3 died.

"The following particulars were ascertained. On January 20th, 1893 , M. and Mme M. bought a parrot from a travelling tradesman; this bird was ill at the time of purchase, and it died on January 25th. It was thrown in the dustbin, and the porter was ordered to clean the cage. All the persons subsequenty ill had been in contact with the sick parrot, and more particularly Mme M., who had fed the parrot from her mouth; the porter had cleaned the cage, which was very dirty from the severe diarrhoea which the parrot had in its last moments of life."

In 1896 Gilbert and Fournier ${ }^{7}$ described further epidemics, and concluded that they were dealing with "a specific- microbic illness, which may appear frequently among parrots, and which can be transmitted to man with great ease." 'Sicárd ${ }^{5}$ in 1897 described a family epictemic that oceurred at Vassy; and Nicolle ${ }^{9}$ in 1898 described a similar epidemic in Bemay. The cause of the latter epidemic was a sick parrot which was sent from Paris, and which died a few days after its arrival. In a review in $19 \mathrm{C} 6$ Gilbert and Fournier" conclude that "the transmission of psittacosis to man is no longer in doubt; it occurs more easily, when the animals are the receivers of particular care, especially coddling aud mouth-to-beak feeding."

Following upon the Paris epidemics, outbreaks also occurred in Italy, and the Rome correspondent of the Lancet $^{10}$ in 1857 quotes a manifesto of the Civic Ufficio d'Tgiene, in which it is stated that " two parrots, recently arrived in Genoa, by the steamship Manilla, set up two 'focolai' (centres of infection) of the aforesaid disease, and this has caused a number of victims." . It is reported that there were 14 cases, 8 of them fatal. This was followed by further outbreaks at Florence, and later at Udine.

In 1899 Leichtenstern ${ }^{11}$ reported further epidemics in Germany, especially in Cologne. He quotes Haedke's observation of a small outbreak in Stettin in 1886, where four members of a well-to-do household were infected from a sick Amazon parrot. There were several outbreaks in Cologne in 1898. The first occurred in a perfectly conducted hygienic household in Quirinstrasse, consisting of mother and father, six daughters, and two sons. Of these ten people only the youngest daughter, aged 14, escaped infection. Four of the nine patients died. The sick parrot was a green Amazon from Brazil. The bird died. A similar type of parrot, also recently imported, caused an outbreak among another Cologne family of the name of Laurenzi. Eight people were taken ill, but only one died. A further outbreak occurred in Bismarckstrasse, there being five cases and one death. This house epidemic was attributed to two recently imported grey parrots. The Krefeld epidemic of 1899 (i1 cases in a hotel) is of interest in that the birds concerned were sick popinjays and finches.

In 1904 Vickery and Richardson ${ }^{12}$ reported i small family epidemic of psittacosis in America. McClintock ${ }^{13}$ (1917) records an epidemic in Wilkes-Barre, Pennsylvania, which originated in the basement of a large department store. Many of the parrots were ill when they arrived at the store, and.a large number died a few days later; many of the parrots were sold. A careful analysis-was made of the clerks located near the parrots.

"In about ten days the sick list of the store employees began to grow. At about the same time many peculiar cases of illness appeared in the practices of physicians in Wilkes-Barre and the surrounding towns. The patients usually gave a clear history 
of contact with the sick parrots, either at the store or at home. .. S Some people touched the parrots, but. in the majority of instances the inspiration of the air of this zone was the conimon factor.... There were a number of human cases in which the disease in its cpidemic form must have been contracted from sick parrots, after the birds had been taken to the homes."

In this country Beddoes:-1 described two cases, aunt and niece, that occurred in 1914. A sailor relative brought home a sick parrot from his ship. Several of the sailors were unwell, and one was taken to hospital at Liverpool with supposed typhoid. In 1924 Gulland ${ }^{15}$ reported two cases in this country, and in 1927 Stollsind ${ }^{16}$ recorded a further two cases. In July, 1829, Thomson ${ }^{17}$ investigated a small outbreak of four cases occurring in Birmingham. It is of great interest to note that psittacosis in the summer of 1929 occurred in epidemic form in the Argentine. This suggests that the mode of transit of the parrots from the Argentine to Europe is not necessarily responsible for the initiation of the disease, but rather for its spread among the birds.

Weekly Bulletin No. 48 of the Health Section of the League of Nations, dated November 28th, 1929, states that according to unofficial information received from the Argentine there was an outbreak of psittacosis in October, and cases of this disease were reported from various parts of the country. The epidemic is said to hare begum at Cordova, among a theatrical company possessing a parrot which was suffering from the disease.

The Epidemiological Record of the Iseague of Nations, December 5 th, 1929 , states :

"Argentine medical journals contain some details concerning the cpidemic of psittacosis which broke out in that country at the end of the summer. During July and August the town of Cordova reported many cases. Psittacosis was only diagnosed a considerable time after it had made its appearance, when the source of the contagion was traced to a disease of parrots. A few days after the epidemic started at Cordova there was another ontbreak at Alta Gracia, a watering place 35 kilometres from Cordova. Another epidemic was notified in the town of Tucuman, also situated in the interior of the Argentine where the Andes rise. This town is directly connected by rail with Cordova. Lastly, cases have been recorded at Buenos Aires. Altogether several hindreds of cases-all connected with sick parrots-have been recorded in the Argentine. Accordingly this seems to be the largest epidemic of psittacosis hitherto known. A committee of inquiry has been appointed by the Tucuman Council of Health, and another inquiry is being carried out by the Argentine Medical Association."

During the last few months epidemics of psittacosis have occurred in the United States of America, in many parts of Europe, and in this country. Thomson ${ }^{18}$ of Birmingham has studied a fresh series of cases, and we have investigated 27 cases, of which 18 occurred in London. Most of these cases have been caused by recently imported green Amazon parrots, and it would thus appear that the pandemic among parrots in South America is largely responsibie for the subsequent European outbreaks.

\section{LONDON HOSPITAL SERIES.}

Group A. (Walworth, London.)

In this group five people were affected, of whom Mr. and Mrs. M. lived in the house, Mr. B. came to work there every day, and Mrs. O'N. and Mrs. S. visited.

The place was a public-house, and on November 8th a green Amazon parrot was bought from a hawker over the counter. The bird sickened and died on Deromber 8 th, when it was replaced by another parrot, which was bought in similar fashion, and which died on December 22nd. The parrot was petted and fed by Mr. and Mrs. M., in the latter case from mouth to beak.

Mrs. M. was taken ill on December 21st, and her husband on the following day. The next to fall ill (December 23rd) was the potman, Mr. B. His degree of contact with the birds is not definitely known, except that he handled both the birds after their death. Mrs. O'N. began to feel unwell at the beginning of January (? 4th). She handled the dead parrot on December 22nd. Mrs. S. fell ill on January 12th. Apparently she had never touched the birds or fed them, but had stood sometimes by their rage. However, it would appear that she was not their ill until twenty-one days after the death of the second parrot, a period much longer than the ninal incubation period. She had nursed Mis. M. throughout her illness, and had, from alleged centimental reasons, used the same handkerchief as Mrs. M. We are inclined to regard her as a case of infection from one person to another. The other four cases were apparently directly infected from the parrots. The three women were sisters.

Of the five patients the potman, Mr. B., an alcoholic indiridual, succumbed after a brief illness; the remaining four were all seriously ill, with danger to life, but eventually recovered.

CASE 1.

E. M., female, aged 43. This patient was iaken ill with general malaise on December 21st, 1929. She continued thus mil December 25th, when she developed a painful dry cough and a pain in the right side. On examination she was found to have an impaired percussion note and crepitations at the right base. The temperature was $102^{\circ} \mathrm{F}$., with slight increase in pulse and respirations. About this time the patient suffered from photophobia and deafness. Within the next few days the pulmonary signs and symptoms increasel in intensity, the temperature being maintained at about $104^{\circ} \mathrm{F}$., the pulse becoming rapid, freble, and irregular, and the respirations increasing to as much as 60 a minute. The physical signs were those of a broncho-pneumonia. The patient became very somnolent, collapsed, and cranosed, and cardiac stimulants and oxygen were used. She remaincd in this precarious condition for about a week, and then began to show slight improvement. On the eighteenth day of the illness the temperature began to fall slowly (lysis), but the lung signs did not clear up for several days after this. At the height of the illness blood cultures were sterile, and the blood count showed a leucopenia. Agglutinations to typhoid, paratyphoid $A$ and $B$, and B. acrtrycke were negative. Convalescence was slow and tedious.

CASE 2.

R. M., male, aged 54, fell ill about December 22nd, 1929, but was not seen by a doctor until December 25th. He then had high fever, with persisicnt cough, but no signs in the lungs. The next day the temperature was $104^{\circ} \mathrm{F}$, and dullness and moist sounds were present at the right base. The patient was semi-comatose and delirious, with outbreaks of restlessness and noisiness. Constipation and distension of the abdomen wer's marked features. The high temperature was maintained for about ten days, after which it gradually fell to normal, and the lung condition resolved. At the end of the first week of the illness the patient dereloped very obstinate hiccup, which persisted for some days. Convalescence was slow and tedious.

\section{CASE 3.}

J. O'N., female, aged 49, began to feel unwell on Jamuary 4 th without having any very definite symptoms. She developed a slight cough after a few days, and took to bed on January 11th. She then complained of severe froutal headache, weakness, cough with slight sputum, sore throat, and photophobia. She became restless and feverish at night, and was unable to sleep. Constipation was troublesome. The patient was not seen by a doctor until January $16 \mathrm{th}$, when her temperature was $101.4^{\circ} \mathrm{F}$., her pulse rate 92 , and respiration rate 25 . Headache was now very severe, a dry cough had become worse, and there were a few crepitations at the base of the right lung. When risited on January 18th the patient lay quietly in bed with all the blinds drawn, as she could not bear the light. She complained bitterly of her headache, which was not relieved by analgosics. It was stated that she had periods of delirium. The lung signs were the same as on January 16th. The spleen was not palpable. The temperature had fallen to $100^{\circ} \mathrm{F}$. that morning, but the next day the patient had a rigor and the temperature rose to $103^{\circ} \mathrm{F}$. It persisted at this level, with only slight morning renissions, for another wenk, after which it fell by lysis. The respirations and pulse were never markedly raised. On January 21st there were numerous moist sounds at the base of both lungs and extcnding up to the scapula. There was slight dyspnoea and some cranosis. The patient occasionally lapsed into a muttering delirium. On January 31st the temperature was normal, although the patient still seemed slightly incoherent, and as though she dirl not fully realize what she was doing. On February 2 nd there was a rclapse, the temperature rising to $102^{\circ} \mathrm{F}$., following upon a rigor. This apparently was associated with a thrombosis of the right femoral vein. The next day the temperature was subnormal. The patient then gradually improved, and on February 11th was convalescent, although the leg was still swollen. Agglutination tests for typhoid, paratyphoid $A$ and $B$, and $B$. acrtrucke were negative during the second week.

\section{Case 4.}

M. S., female, aged 56, was taken ill on January 12th with general malaise and weakness. On the second day a severe headache and backache developed. Her temperature was $104^{\circ} \mathbf{F}$., her respiration rate 24 , and her pulse rate 98 . On January 14 th the 
patient was very confused and complained of vague abdominal pain, chiefly in the iliac regions. Apart from some distension of the abdomen there were no definite physical signs at this time. The next day the confusion and collapse increased and there were periods of delirium. On one occasion she jumped out of bed and rang a bell, afterwards stating that she had no reason for doing so. The patient was very restless at night, and could not sleep. The headaches persisted in spite of numerous analgesics. A troublesome dry cough developed. Constipation and anorexia were well marked. Photophobia was present. On January 19th (seventh day of illness) she was admitted very ill to the London Hospital. She lay in a semi-comatose condition, without taking any interest in her surroundings, even when aroused. Her cheeks were flushed and her tongue dry and furred. There were some moist sounds at the base of the right lung. The abdomen was distended, and the spleen was not palpable. Her temperature was $103^{\circ} \mathrm{F}$., her pulse rate 92 , and respiration rate 24 . She remained in this state for about a week, the delirium and troublesome dry cough being prominent features. The moist sounds at the base of the right lung increased, and on January 27th the percussion note was impaired and an area of tubular breathing was present at the angle of the right scapula. At this time (fifteenth day of illness) the temperature was falling by lysis, and on January 28th it became subnormal, persisting at this level until the patient's discharge, two weeks later. During the first week of the afebrile state the patient's general condition was precarious, but subsequently there was gradual recovery. Moist sounds were present in the lung for about ten days after the temperature had fallen. Agglutination tests on January $20 \mathrm{~h}$ were negative for typhoid, paratyphoid $A$ and $\mathrm{B}$, and $B$. acrtrycke, and blood cultures were sterile. The urine contained a trace of albumin, leucocytes, and epithelial cells, and gave cultures of $B$. coli and $B$. proteus. A blood count on the eighth day showed: erythrocytes $4,700,000$ per c.mm.; haemoglobin 64 per cent.; colour index 0.65 ; leucocytes 5,760 , polymorphs 81 per cent., eosinophils 0.5 per cent., small lymphocytes 12 per cent., large lymphocytes 1 per cent., large hyaline cells 5.5 per cent.

\section{CASE 5}

F. P. B., male, aged 53, began to feel unwell on December 23rd, but continued at his work until the $28 \mathrm{th}$, when he complaincd of very severe headache and aching in all his limbs. He was admitted to an institution on December 30th with a temperature of $102^{\circ} \mathrm{F}$., a pulse rate of 88 , and a respiration rate of 24 . He then had a slight cough, and a few moist sounds were noted in the lungs. Insomnia and marked constipation were other symptoms at this time. The headache persisted and the cough became more troublesome. On January 6th fine crepitations were present all over the right lung. On January 8th there appeared signs of bronchopneumonia at the bases of both lungs. It was specially noted that in spite of a persistently high temperature, the pulse had remained relatively slow, 80-100. The respirations, too, were only 24 . A large, bright haemorrhage now occurred from the rectum. During the next few days the patient became worse, the respirations and pulse increasing. He died on January 11th. Necropsy showed lobar pneumonia of the whole of the left lung and right lower lobe, and it was thought that the patient died from influenzal pneumonia and heart failure. The case was subsequently traced as one of this group of five cases, and it would appear from tho records and charts that it was much more probably a case of psittacosis with marked involvement of the lungs, as usually occurs in fatal cases of this disease.

\section{Group B. (Barking, Isondon.)}

In this group five people were affected-two sisters, two brothers, and the mother, all belonging to one family. Apart from one of the sisters, who was married, they all lived in the same house. It is interesting to note that, whereas all these people were previously in good health, two remaining members of the family, brother and sister, suffering from phthisis and living in the same house, gavo no evidence of infection with psittacosis. Two other sisters, however, also escaped infection.

J. R. bought a green Amazon parrot from a hawker in Spitalfields Market on January 10th. Although showing no gross signs of illness, it fell off its perch dead on January 21st. The patients at first considered that they had had no intimate contact with the bird, but it subsequently appeared that, except for the married sister, they had in all probability put their fingers inside the cage and stroked the parrot's head.

I. R. fell ill on January 23rd, F. R. on January 25th, J. R. on January 27th, El. R. on February 1st, and E. S. on February 6th. The first four cases appear to be direct infection from the parrot, but the last case, that of the married sister, is much more probably an example of personto-person infection. She saw the parrot on only one occa- sion, January 12th-that is, twenty-five days before the beginning of her illness. She came to live with the $\mathbf{R}$. family from February 1st, in order to nurse her mother, but she had called on the other ill patients and sat by their bed in the house for some dars previous to this. The severity of the infection in this ill-fated family was very great, pulmonary complications being a marked feature. Only two survived-the married sister, E. S., and one brother, J. R.

\section{CASE 1 .}

L. R., fcmale, aged 30, was taken ill on-January 23rd. She awoke in the morning feeling unwell, and at 7.45 , on taking a cup of tea to her mother, she suddenly fainted on the bed. After a few minutes she recovered conscioasiness, and returned to her own bed feeling ill and very weak. For the next few days the paticnt suffered from very severe headaches, photophobia, insomnia, nausea, and a dry troublesome cough. On January 26 th the patient vomited twice, and on the $28 \mathrm{ch}$ she was admitted to the London Hospital, all the symptoms having persisted.

On admission her temperature was $102^{\circ} \mathrm{F}$., her pulse rate 120 , and respiration rate 36 . She was cyanosed and had sordes on the lips. Numerous rhonchi were scattered throughout the lungs, and crepitant rales were present at both apices. There was no dullness on percussion. The tongue was dry and coated, and th abdomen distended. The spleen was not palpable. There were no objective changes in the central nervous system.

The headache gradually diminished in intensity, but the cough became more troublesome, sputum still being absent. There was no marked constipation or diarrhoea. On January 30th dullness and diminished breath sounds, with moist sounds, were noted at the base of the left lung. The cyanosis had increased. During the last few days the patient had become very lethargic, and she was now semi-conscious. The dyspnoea and cyanosis had increased. On February 2nd she became unconscious, and after some hour in this state died. The day before death her temperature was $102^{\circ} \mathrm{F}$., pulse rate 108 , and respiration rate 60 .

Agglutination tests for typhoid, paratyphoid $\mathbf{A}$ and $\mathbf{B}$ and B. aertrycke were all negative (January 31st), and blood cultures were sterile. The urine and faeces gave cultures of B. coli. A blood count on January 30th showed : erythrocytes $5,100,000$ per c.mm.; haemoglobin 83, per cent.; colour index 0.82 ; leucocytes 10,040 , polymorphs 93 per cent., small lymphocytes 4.5 per cent. large lymphocytes 1.5 per cent., large hyaline cells 1 per cent.

CASE 2.

E. R., male, aged 18, awoke on the morning of January 25 th with a slight headache. He did not have any breakfast, but went to work. During the morning the headache became very much worse. It was mainly situated in the parietal region, but sprearl across the top of the head. He was unable to continue at work, and at 2 p.m. took to his bed, complaining of the headache weakness, and vague pains all over the body. During the next few days the headache became worse, constipation was troublesome, and a worrying dry cough developed. On January 28th he was admitted to hospital. He was obviously very ill, but there was no mental cloudiness at this time. The temperature was $102.5^{\circ} \mathrm{F}$., the pulse rate 120 , and the respiration rate 36 . There was no marked photophobia. Sonorous rhonchi were present at the bases of both lungs. The abdomen was not markedly distended, and the spleen was not palpable. 'The heart was apparently normal, and no abnormalities were found on examination of the central nervous system.

On January 29th there was considerable epistaxis, which recurred frequently during the next few days. At this time he began to expectorate some muco-purulent sputum, and increased respirations were very evident. He became very restless at night, and the next day had periods of delirium and disorientation. On January 30 th he was definitely cyanosed and somewhat collapsed. Dullness and bronchial breathing were present at the inferior angle of the right scapula, with intense whispering pectoriloquy and crepitant rales. The patient gradually became semi-conscious, with periods of restlessness and excitement during which he was restrained with difficulty from leaving his bed. On February 3rd he was very collapsed and stuporous. There was no response to questions, although he made a slight attempt to put out his tongue on being asked to do so. There were definite signs of consolidation at the base of the right lung-marked dullness and bronchial breathing. There were a few moist sounds at the left base, and numerous rhonchi scattered throughout the rest of the lungs. He was still having attacks of severe epistaxis. On February 5th his condition was even worse; he was almost unconscious, except for intermittent periods of violent excitement. The signs in the lungs were the same. The patient fell more and more deeply into coma, and died on February 9th.

On January 28th and February 5th agglutination tests were negative for typhoid, paratyphoid $A$ and $B$, and $B$. acrtrycke blood cultures were sterile. A blood count on January 30th showed: erythrocytes 5,100,000 per c.mm.; haemoglobin 90 per cent.; colour index 0.89; leucocytes - 7,120 per c.mm., polymorph 
71 per cent., small lymphocytes 18 per cent., large lymphocytes 3 par cent., large hyaline cells 8 per cent. Another blood count on February 5th was very similar, the leucccyte count being 6,520 per c.mm.

\section{CASE 3.}

J. R., male, aged 27, fell ill on January 27th, with throbbing frontal headache, which persisted with severe exacerbations; especially at night. He retired early to bed that day, and, althongh he got up the next morning, he returned to bed at midalay. That evening he felt very sick and retched for several hours. On January 30th he was admitted to hospital with a temperature of $101^{\circ} \mathrm{F}$.; a pulse rate of 94 , and respiration rate of 24 . The temperature remained high for three days, and then fell within twenty-four hours to normal (February 3rd). The only complaint during the illness was the headache. There was no cough, although the lungs showed transient impaired note and diminished breath sounds at the right base, with a few scattered rhonchi. There was no marked abdominal distension, and the spleen was never palpable. There was no photophobia. Although the patient was usually quite clear mentally, he seemer slightly delirious at intervals. On February 2nd he had a profuse epistaxis. The next day he felt much better, and had a fairly rapid convalescence. Blood cultures on January 30th were sterile. Agglutination tests on February 5th were negative for typhoid, paratyphoid $\mathbf{A}$ and $\mathbf{B}$, and $B$. acrtryckc. The faeces gave cultures of $\dot{B}$. coli. A blood count on January 30 th showed : erythrocytes $5,000,000$ per c.mm.; haemoglobin 80 per cent.; colour index 0.8 ; leucocytes 7,000 per c.mm., polymorphs 70 per cent., small lymphocytes 17.5 per cent. large lymphocytes 5 per cent., large hyaline cells 7.5 per cent.

CAsE 4.

El. R., female, aged 52, fell ill, on February 1st, with headache and malaise. That day she had an attack of shivering, especially along the spine. This lasted for about one hour, and disappeared when she was well covered in bed. On February 2nd her temperature was $102^{\circ} \mathrm{F}$, her pulse rate 100 , and respiration rate 24 . She developed a slight dry cough on this day, but there were no physical signs in the lungs. Photophobia was present. The bowels werc constipated. On February 4th the patient was still quite clear mentally and not very ill. The cough had persisted, and there were several moist sounds at the hase of the left lung. Her headache bccame worse during the evenmg, and she described it as throbłing and sore as if someone had been beating or scraping the top of the head. The headacte was greatly aggravatcd by coughing.

During the next two days s'ce complained of profuse sweating, and stated that the headaches made her light-headed. She found herself talking nonsense on awaking. On the morning of February 5th sie vomited, and on February 6th she was admitted to the London Hospital. She was now bringing up much muco-purulent sputum and the photophobia was well marked the blinds being drawn by request. The headache was not a prominent feature at the time. The lips were scmewhat cyanosed, and sordes were present round their margins. The throat was red, and there was a yellowis!! exudate on the soft palate; slight conjunctivitis was present. The tongue was dry and furred, and the abdomen was distended. The spleen was not palpable. Crepitations were present at the base of both lungs, and rhonchi were scattered throughout. The heart sounds were normal, and there were no abnormal objective signs in the nervous system. On the day of admission her temperature was $104^{\circ} \mathrm{F}$., pulse rate 24 , and respiration rate 26 .

On February 7th there were periods of slight delirium. There was a patch of bronchial breathing near the angle of the right scapula. On February 9th there was still much muco-purulent sputum, and the percussion note at the left base was dull. During the next few days respirations increased to 40 or 50 ; the patient became much worse, falling into a semi-stuporous condition. On February 1.3th $30 \mathrm{c.cm}$. of cerebro-spinal fluid were obtained under pressure, and $40 \mathrm{c.cm}$. of convalescent serum were injected intramuscularly. The patient died that day.

At the end of the first week blood cultures were sterile, and agglutination tests were negative to typhoid, paratyphoid $A$ and $B$, and $B$. acrtrycke. The urine and faeces gave cultures of $\boldsymbol{B}$. coli. A report on a swab from the throat showed: Vincent's angina organisms, pneumococci, streptococci, and sarcinae. Blood count : erythrocytes 5,000,000 per c.mm.; haemoglobin 75 per cent.; colour index 0.73 ; leucocytes, 3,360 per c.mm., polymorphs 75 per cent., small lymphocytes 16 per cent., large Jymphocytes 5.5 per cent., large hyaline cells 3.5 per cent.

\section{CASE 5.}

E. S., female, aged 28, fell ill, on Fe'Jruary 6 th, with violent generalized headaches, sore throat, weakness, and slight cough with some muco-purulent sputum. The next day photophobia developed, and she stated that distant objects appeared double when seen in the light. The headaches continued to be very severe, and the patient became sommolent during the day and restless at night. She was admilted to hospital on February Gth, the third-day of the illness; her temperature was $102^{\circ} \mathrm{F}$., pulse rate 124 , and respiration rate 40.

Although scmewhat lethargic the patient's intellect was apparently quite clear. There was some cyanosis and respiratory distress. The cough was very persistent and troublesome; and there was some grey muco-purulent sputum. The tongue was dry and furred, and the throat was infected. The abdomen was distended, and the splcen was not palpable. The percussion note was slightly impaired over the right middle lobe, and moist sounds were heard over this area, extending anteriorly to the level of the second rib. The patient was eight months pregnant.

The next day the patient had two shivering attacks, or:c. : $t$ 3 a.m. and the other at 8 p.m. The throat was very troublesoms, but though it was congested there was no obvious exudation. On February 11th there was a further rigor in the early morning, and the photophobia necessitated an eve-shade.

Examination on February 12th showed extension of the lung infection to the base of the right lung, where there were numerous moist sounds. The headaches and sore throat persisted, but the pliotophobia gradually diminished. At 3 a.m. on February 16th there was a further rigor. Examination that day showed a patch of dullness and tubular breathing at the vertebral border of the right scapula. This area became more extensive the next day, and on Ferruary 18th the right base gave a dull percussion note, with tubular breathing, moist sounds, whispering pectoriloquy, and oegophony. The patient's general condition, however, was on the whole better. She stated that throughout her illness she had great difficulty in kceping awake, but on falling asleep she found that she began talking to herself and muttering. The respirations remained high, the pulse rapid, and the temperature of a swinging variety. The lung signs began to clear up on February $20 t h$, when the temperature reached normal after an irregular fall. Convalescence was normal. Blood cultures, and agglutination tests for typhoid, paratyphoid $\mathbf{A}$ and $B$, and $B$. aertrycke, were negative at the end of the first week. The urine was sterile, but the faeces gave cultures of $B$. coli. The sputum contained pneumococci, streptococci, and Micrococcus catarrhalis. A swab from the throat gave cultures of Micrococcus catarrhalis, with a few pneumococei al:d streptococci.

\section{Group C. (Barking, London.)}

This was a small group consisting of husband and wife, Mr. and Mrs. S., who lived in a pablic-house. The parrot, a green Amazon, was bought over the counter, during the latter part of October, from a hawker, who had obtained it from the docks. The parrot was ill for about one month with diarrhoea, sncezing, loss of appetite, and wasting, and on Decenber 12th, after an attack of convulsions, it fell off its perch and died. Both patients fell ill about November 21st, and both recovered after being scverely ill. The association with a sick parrot did not come to the knowledge of the physician in charge until the period of convalescence.

Case 1.

A. S., male, aged 32, fell ill on Novembcr 21st, when he felt somewhat "shivery and out of sorts:" The next day he had a severe frontal headache which persisted, slight sore throat, and romiting. On November 25th there was slight epistaxis, and the day after this the patient experienced severe cramp in the legs. The appetite throughout had been very poor. Constipation was obstinate, there having been no action of the bowcls for a wcek.

On November 28 th the temperature was $10 \mathrm{~L}^{\circ} \mathrm{F}$., pulse rate 100 respiration rate 28 . The patient looked ill and collapsed, his general appearance simulating a typhoid state. The tongue was dry and furred; the throat was injected, and thcre were patches of yellowish membrane on the palate. A few small rose-coloured spots were scattered over the chcst. There was no dullncss on percussion of the chest, but auscultation revealcd crepitations at the right base and a few rhonchi at the left base. At this time there devcloped a slight cough with mucoid expectoration; no rusty sputum. Examination of the heart revealed nothing abnormal. The abdomen was somewhat distended, but the spleen was not palpable. A quarter rolume of albumin was present in the urine. The patient's condition did not improve during thenext week, the temperature swinging from $101^{\circ}$ to $104^{\circ} \mathrm{F}$., the pulse rate being relatively slow, between 82 and 112, and the respiration rate ranging from 24 to 30

On December 3rd examination of the chest showed slight dullness, diminished breath sounds and medium crepitations at the right base, and signs of bronchitis at the left base. From December 5th to 8th the condition of the patient gradually improved, and on December 8th the temperature fell by lysis, and remained normal. At that time the abnormal signs in the chest had disappeared. The albumin in the urine gradually diminished to a faint trace. The patient made an uninterrupted recoiery.

On January 1st and 8th blood cultures, and agglutination tests to typhoid, paratyphoid $\mathbf{A}$ and $\mathrm{B}, \boldsymbol{B}$. acrtryck, and B. cntcritidis, were all negative. 


\section{CASE 2.}

M. S., female, aged 27, felt ill about November 22nd, complaining of headache, cough, nausea, constipation, and occasional vomiting. She took her own temperature on several occasions, and once it was as high as $102^{\circ} \mathrm{F}$. When seen by her private doctor on November 27th she complained of severe frontal headache, weakness, aching of body and limbs, and inability to lift her head from the pillow on account of giddiness. Her temperature was $103^{\circ} \mathrm{F}$., pulse rate 110 , and respiration rate 24 . The patient was obviously very ill, and lay in bed in a collapsed stuporous state. The tongue was dry and furred, and the fauces red and inflamed. No abnormal physical signs were discovered in the lungs at this time; the heart and abdomen were normal; the liver and spleen were not palpable. Examination of the nervous system was ncgative.

The patient remained in this condition for a period of six days; the cough became very troublesome, the headache continued, and fever ranged between $101^{\circ}$ and $103^{\circ} \mathrm{F}$. On the morning of the seventh day, however, the temperature was $100.8^{\circ} \mathrm{F}$; the patient felt better and had less headache; she had siept better during the night, and the aching of the limbs was not so intense. On the evening of this day the temperature remained the same, but the patient maintained improvement. On the morning of the eighth day she complained of some pain over the right lower chest, and on examination a few crepitations were heard in the lower lobe of the right lung. The patient continued to make progress quickly during the next few days, until on the eleventh day her temperature ranged about $98.4^{\circ} \mathrm{F}$. and her pulse rate was 90. The fever abated by lysis. The physical signs in the lung persisted for about seven days after they were first discovered. The patient remained in bed for eighteen days, and convalescence was uneventful.

In the second week of the illness blood cultures, and agglutination tests to typhoid, paratyphoid $\mathrm{A}$ and $\mathrm{B}$, and $B$. acrtrycke, were all negative.

\section{Group D. (Oxford and Lonton.)}

This group consisted of five people staving in a country house in the Chilterns. Three other members of the household, although in contact with the parrot, escaped infection. A green Amazon parrot arrived at the house on December 21st, having been purchased from a London shop; the bird was never well, and died on December 30th.

Mrs. M. fell ill on January 5th, M. W. (cook) on January 7th, G. F. (a friend) and X. M. (a nephew) on the 10th, and A. B. (gardener) on about January 10th or 12th. Mrs. M., G. F., and A. B. were definitely known to have handled the parrot, the latter only after its death. M. W. had:at least been near the bird on several occasions during life, but $\mathbf{X}$. M. apparently merely sat in a room from which the dead parrot had been removed two hours previously. One of the patients returned to London before she fell ill, and her case is described in some detail below. We only refer briefly to the remaining four cases, as they have already been described in the British Medical .Journal by Dr. Mary Radford. ${ }^{19}$ All the patients recovered after being very ill.

\section{CAse 1.}

A. F., female, aged 49 , returned home from the Chilterns on January 3rd, and was quite well until January 11th, when she suddenly began to feel very cold and to shiver. The shivering lasted twenty-four hours, and at the same time she experienced a very severe general headache, which persisted for a week, and then gradually got better. Her temperature was found to be $102^{\circ} \mathrm{F}$., pulse rate 90 , and respiration rate 26 . There was no photophobia or epistaxis. A troublesome cough was present from the first, the patient feeling somewhat stifled and experiencing a sense of constriction behind the upper part of the sternum.

On January 16th there were signs of congestion at the base of the left lung. The next day there were numerous crepitations extending up to the angle of the scapula. The patient had been very constipated throughout, and the abdomen was distended. The spleen was never palpable, and there were no red spots. The patient became very restless at night, with intermittent delirium and insomnia.

On January 23rd the right lung became involved, and crepitations and patchy dullness were present at both bases. The patient's general condition, however, was beginning to show signs of improvement. Some nasal catarrh was present. On January 25th the patient further improved, though patchy dullness and crepitations were still present at both bases. The temperature was beginning to fall. Throughout the illness tho respirations were not raised, and the pulse was relatively slow. On January 29th the temperature was normal, but the signs in the lungs did not disappear until February 15th. Convalescence was slow.

Agglutination tests for typhoid, paratyphoid $A$ and $B$, and B. aertrycke were negative on January 23 rd and 28 th.
Case 2.

Mrs. M., aged 50 , fell ill on January 5 hh, and recovered after a characteristic illness of three weeks' duration. Negative agglutinations.

CASE 3.

M. W., female, aged 65 , fell ill on January 7th. This patient, cook in the household, had the usual symptoms and signs, and eventually recovered. Negative agglutinations.

\section{CASE 4.}

X. M., nephew, aged 43 , fell ill on January 9 th or 10 ih, and began convalescence after sixteen days. There was a partial agglutination to typhoid ( 1 in 32$)$ in this case, but this may be explained by inoculation with T.A.B. in 1916 .

Case 5.

A. B., gardener, aged 56, fell ill about January $12 \mathrm{th}$, and recovered after a few weeks' characteristic illness. A temporary relapse occurred during convalescence. Agglutination tests (including $B$. (abortus) were all negative.

Grovp E. (Hampstead, London.)

A green Amazon parrot was bought from a large Iondon shop on October 23rd, 1929. From the first the bird hat diarrhoea and its feathers were not properly "set." The parrot was taken back to the shop after the patients becamo ill. The two people affected had both been in contact with the parrot, one cleaning out the cage. The first pationt, a doctor, fell ill on November 19th and died on December 10th. The second patient, his maid, was less severely affected, falling ill on November 26 th and recovering after a few weeks.

\section{Case 1.}

D. L. T., male, aged 60 , was taken ill on November 19th with sudden onset of general malaise, aching all over, and "feeling as if I had a temperature." Next day his symptoms were worse, he felt feverish, and his temperature was $101^{\circ} \mathrm{F}$. He complained of severe headache, and said he thought he had influenza, but was surprised that he had no-catarrhal symptoms or signs.

On November 27 th his temperature was $102.5^{\circ} \mathrm{F}$., pulse rate 85 . and respiration rate 25 . His tongue was furred; he was mentally very depressed, and complained of severe headache. No abnormal physical signs were detected in the heart, lungs, abdomen, or nervous system. The urine was clear. A blood count on November 29th showerk: leucocytes 6,750 per c.mm., polymorphs 72 per cent., lymphocytes 26 per cent., transitional cells 1 per cent., eosinophils 1 per cent. The agglutination reaction was negative for typhoid and paratyphoid $\mathbf{A}$ and $B$.

On November 30th he was admitted as an in-patient to the Londoin Hospital, $\mathrm{He}$ was then slightly dyspnoeic; there was also a little blood-stained discharge from the nose; he was drowsy, but quite rational, and still complained of severe headache. There were no abnormal physical signs detected in the lungs. Blood examination showed : erythrocytes $4,900,000$ per c.mm.; haemoglobin 80 per cent.; colour index, 0.81 ; leucocytes 10,280 per c.mm.; polynuclear neutrophils 66.5 per cent., eosinophils 2.5 per cent., small lymphocytes 17.5 per cent., large lymphocytes 7.5 per cent., large hyaline cells 6 per cent. There was slight anisocytosis.

On December 2nd he had retention of urine, but complained of no real pain referred to bladder or perineum. He was catheterized, and 32 ounces of urine were withdrawn. It was examined and reported on as follows: "Acid; albumin a cloud; no reduction with Fehling; deposit contains leucocytes and epithelial cells; cultures yield Staphylococcus albus." Nothing abnormal was detected in the nasal and accessory sinuses, but there was a good deal of inflammation of the nasal mucous membrane.

On December 5th he was not so well; more drowsy, greater dyspnoea, and more severe frontal headache. His temperature was $104.5^{\circ} \mathrm{F}$ :, pulse rate 112 , and respiration rate 44 , The respiratory movements were rapid and shallow. Heart sounds were clear; coarse crepitations were audible for the first time over the lower lobe of the right lung; no rhonchi were heard. The percussion note was not impaired, and the breath sounds were vesicular. The abdomen was slightly distended, there was no tenderness or rigidity ; the liver and spleen were not palpable. Rose-coloured spots were visible on the lower chest, and these disappeared on pressure.

Agglutination tests were negative for typhoid, paratyphoid A and B., B. aertrycke, B. entcritidis, Micrococcus melitensis, and B. abortus.

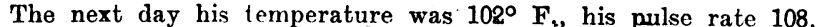
and respiration rate 40 . In the morning he seemed fairly well; he was reading his newspaper and talked quite rationally. The sputum was definitely rusty, dyspnoea greater, and there were more definite signs in the lungs. The percussion note over the lower and middle lobes of the right lung was impaired; coarse crepitations and pleural friction sounds were audible over the same area. Three rosecoloured spots were still visible on the upper abdomen and chest. 
$X$-ray examination of the chest gave the following information: "No obvious dullness on the screen; rather poor and diminished moiement of the right diaphragm, possibly slight dullness, suggestive of a possible pleurisy, over right lower ehest. No evidence of eifusion."

On December 7th the sputum was blood-stained, the skin dry and hot, and he had greater dyspnoea. In the evening his condition was much worse; he took no notice of anyone around him. His temperature was $104.5^{\circ} \mathbf{F}$., pulse rate 120 , and respiration rate 56. Report on the urine: deap amber in colour; albumin 1/4; blood and sugar absent. The heart sounds were good. The signs of consolidation in the right lung were more marked.

On December 8th his temperature was $102^{\circ} \mathrm{F}$., pulse rate 118 , and respiration rate 50 . The previous evening he had had a tepid sponging, after which he seemed more rational and had a fairly good night. During the morning he took more interest in people around him, and asked for his drinks, etc. He was very dyspnoeic : his s'in was hot and dry, and his tongue furred and getting dry: For the first time he had urinary incontinence. The heart sounds were good and the blood pressure was $120 / 60 \mathrm{~mm}$. The middle and lower lobes of the right lung showed typical signs of consolidation ; the percussion note was dull, breath sounds were tubular, and no adventitious sounds were audible. Now also a few coarse crepitations were audible over the lower lobe of the left lung. Towards the evening he had a good deal of abdominal distension, which was relieved slightly by a small enema, rectal tube, and injection of pituitrin.

The next day his temperature was $103^{\circ} \mathrm{F}$, pulse rate 110 , and respiration rate 54. He had slept fairly well during the night, but still had urinary incontinence. There was now slight oedema of the feet and ankles. The plyssical signs in the lungs were very much the same as on the previous day. The abdomen was still distended, but no hepatic or splenic enlargement could be detected. His blood pressure was $110 / 65 \mathrm{~mm}$. He was fairly comfortable during the evening and slept well in the early part of the night. At 4.30 a.m. the breathing altered; it became " very rapid and heavy." His pulse failed, and he died at 4.50 a.m. on December 10 th.

\section{CAse 2.}

V. R., female, aged 33, was a maid employed in the house of D. L. T. She complained of general malaise about a week after the beginning of D. L. T.'s illness. She was admitted to the St. Marylebone Hospital on December 1st, 1929, having suffered from malaise, headache, and vertigo from November $26 \mathrm{th}$.

Three days before admission she developed a cough without sputum, and complained of sweating. She felt weak and hot, and had a slight headache. On admission she appeared very drowsy and collapsed, her condition simulating a typhoidal state, and suggesting the preliminary diagnosis of typhoid. The tongue was moist and furred. The abdomen was slightly distended, and the liver and spleen were not palpable. Numerous course rales and rhonchi were heard at the base of the right lung. The cardiovascular and nervous systems were normal. The urine showed no abnormal constituents.

On December 6th the patient had a brief epistaxis. On December 10th there were still numerous crepitations at the base of the right lung, but the general condition was beginning to improve. Throughout the illness she tended to be very constipaled. The cough persisted for about ten days, but there was only slight frothy sputum, which was never rusty. Respirations throughout were usually 20 , and were never above 28 . The pulse was rather slow relative to the temperature. The latter was maintained at $101^{\circ}$ to $103^{\circ} \mathrm{F}$., and fell by lysis. Convalescence was slow and tedious. Agglutination tests during the second week of the illness were negative to typhoid, paratyphoid $\mathrm{A}$ and $\mathrm{B}, \mathrm{B}$. acrtrycke, and $\mathrm{B}$. conteritidis.

\section{Grovp F. (Leatherhead, Surrey.)}

This group consisted of two people, one C. L., who kept a large aviary as a hobby, and the other his gardener, $S . R$., who looked after the birds. In the early pait of September, 1529, C. I. purchased from a London store five birds-.. 2 snall blue macaws, 1 green Amazon parrot, and 2 vellowgreen Amazon parrots. The last two birds fell ill in December, one about December 8th and the other about Decomber 17th. Both birds were in the same cage; but were separated a few days after the first became ill. The latter bird died after some days' jllness, and the remaining one succumbed about two weeks later. The parrot that first fell ill was not well from the start, but appeared to recover after a week or so, although the gardener was of the opinion that it was never quite healthy. During the pediod of acute illness the parrots suffered from diarrhoea, swollen eyes, ruffled feather's, loss of appetite, and inertia.

C. L. fell ill on December 17th and S. R. a few days later. Both fed the birds, but the parrots were not taken from their cage, and there was no mouth-to-beak feeding. Both these patients recovered, and their illness was cnly moderately severe, although quite tvpical. These cases are of special interest in that the parrots were in this country at least three months before becoming rcally ill and infecting man. The dealer stated that they were in England for three ronths before purchase, thus making the total period since importation six months.

Case 1.

C. L., male, aged 70 became unwell on December 17th. He was unduly tired, and slightly nauseated, but went to town as usual on that day and on the next two days. On December 19th he came home early from business because he fit faint and ill, and vomited. On December 20th and 21st he felt very unwell and nauseated, was drowsy, and slept a good deal. When seen on December 22nd he looked ill and thin, his tongue was furred, and he complained very much of nausea, headache, and a feeling of lassitude. He had a slight cough, but stated that this was not unusual; there was some thick muco-purulent expectoration. His temperature was $102^{\circ} \mathrm{F}$., and his pulse 80 , regular, and very soft the systolic blood pressure being only $125 \mathrm{~mm}$. Hg, and the respirations were 25. On examination of his chest the breath sourds at the right base behind were a little weaker than on the opposite side, and there were a few coarse crepitations. The abdomen was soft and normal, no enlargement of the spleen or liver could be detected, and no spots or skin eruption were seen.

On Dacember 26th his temperature fell by lysis, and remairicd normal for four days, after which there was a slight recrudescence of his symptoms, the temperature again rising to $101^{\circ} \mathrm{F}$., when he complained of a little pain in the right lower axillary region, but no physical sign could be discovered in his chest to account for this. Two days later the temperature again became normal, after which he entered upon convalescence.

Agglutination tests on January 2nd were negative for typhoid, paratyphoid $\mathrm{A}$ and $\mathrm{B}, \boldsymbol{B}$. aertrycke, and $\boldsymbol{B}$. enteritidis.

\section{CASE 2.}

S. R., male, aged 48 , felt unwell on December 18th, but had no definite symptoms. On December 20th he began to shiver, and thought he was about to have another attack of malaria, from which he had suffered-since the war. He vomited several times and sweated. A profuse epistaxis occurred on December 21st, and lasted on and off for a few days. His temperature was $102.2^{\circ} \mathbf{F}$., pulse rate 100 , respiration rate 26 . He was given large doses of quinine. The vomiting and shivering persisted for a few days. The quinine appeared to be without effect, the temperature remaining,high. It was noticed that the pulse was relatively slow.

After the first week the patient was still feeling very ill and complained of severe headaches. Delirium was present at night. The quinine was discontinued. At the end of the first week a slight, dry, irritating cough developed. On December 29th crepitations were present at the base of both lungs, and the next day the patient was removed to hospital. Constipation had been troublesome throughout the illness.

On examination in hospital, on December 31st, the patient appeared dull and lethargic. He responded intelligently to questions, but only after an appreciable latent period. His temperature was $102^{\circ} \mathbf{F}$., pulse rate 88, respiration rate 24 . His pulse was regular, and of moderate volume and tension. His tongue was coated and his abdomen distended. The spleen was not palpable. The lung signs had almost disappeared, and there was nothing abnormal in the heart or nervous system. In the evening of December 31st six red spots were seen on the chest and abdomen, a few more appeared on the back the next day, but they all disappeared within five days. The spots were about 2 to $4 \mathrm{~mm}$. in diameter, the centre of them being slightly raised and papular. They faded on pressure, but on rubbing the finger across repaatedly they became more prominent, and were seen to be surrounded by a white halo, with a further thin red line bounding this like a planet.

On January 22nd the patient was still dull and apathetic. Slight cough had persisted; headache was diminishing; the abdomen was still distended. The next day the temperature began to fall by lysis, and on January 5th the patient was greatly improved, being quite bright and intelligent, and responded rapidly to questions in a manner that contrasted markedly with his former condition. He made a slow but uninterrupted recovery.

On January 3rd agglutination tests were negative to paratyphoid $\mathbf{A}$ and $\mathbf{B}, \boldsymbol{B}$. aertrycke, and $B$. enteritidis, but gave a partial agglutination to typhoid ( 1 in 64 ). T'his was probably due to the T.A.B. inoculations that the patient had received during the war. Blood cultures were negative.

\section{CASE G. (London, W.).}

This case is of very gieat interest in that the history of the parrot is known from the time it was caught in its native habitat, and because the evidence strongly favours the view that the bird was a carrier of the disease after 
eight months' residence in this country. The parrot was a grey one, caught fourteen months previously on the Gold Coast of Africa. The bird was ill when caught, and took some weeks to recover. It was subsequently apparently quite well, and was brought to Fngland by the owner in Nay, 1929. While in this country the parrot showed no signs of illness, except for transient attacks of mild diarrhoea, which were attributed to periods of injudicious feeding.

The patient was one day playfully protruding her tongue at the parrot, when the latter caught the tongue in its beak and held it tight for some scconds. The tongue was sore some days after this, but the patient became really ill ten days after this incident, and ran the course of a classical case of psittacosis. She eventually recovered after a very severe illness.

It is interesting to note that the parrot had been petted and played with by several members of the household for some time. It would thus appear that the contact in the case of carrier parrots must be of a much more intimate nature to transmit infection to man than is the case with recently imported sick birds.

\section{Description of Illness.}

L. S., female, aged 44, felt unwell on January 19th and complained of pains all over the body. She tried to relieve "the aching in every limb" by using liniment. The next day she remained in bed, with a very severe headache. She felt very weak, and sweated profusely and shivered at intervals. During the next few days her condition gradually became worse. Drowsiness and photophobia were present.

On January 22nd her doctor found the temperature to be $102^{\circ} \mathrm{F}$., respiration normal, and pulse rate only slightly raised. On January 26th a dry cough developed, and a few moist sounds were found at the bases of both lungs. About that time two rose spots appeared on the abdomen, and persisted for a few days. Constipation was troublesome.

The tongue had been painful and sore from the first, but on January 28th the lips began to swell. This classical sign persisted for about four days, and then gradually disappeared. She was admitted to hospital on January 30 th in a very collapsed condition. Her temperature was $103^{\circ} \mathrm{F}$., pulse rate 100 , and respiration rate 28 . The patient lay quietly in bed, with eyes closed, pallid countenance, and well-marked peribuccal oedema. Moist sounds were present at the base of the right lung. The abdomen was distended, and the spleen was not palpable. During the next few days the hard, dry cough became very troublesome, and paroxysms of coughing left her very exhausted. On February 3rd she was very drowsy and collapsed, and it was doubtful whether she recognized people at the bedside.

On February 5th the temperature fell by lysis to subnormal. For some days after this the patient's condition showed no improvement, and the moist sounds were still present at the base of the right lung. From about February 10th she gradually improved, and on February 20 th was sitting up in bed, talking cheerfully, although far from strong. The patient had no recollection of the greater part of her illness.

Agglutination tests on the eleventh day of the illness were negative to typhoid, paratyphoid $\mathbf{A}$ and $\mathbf{B}$, and $\boldsymbol{B}$. acrtrycke. $\mathrm{A}$ blood count on that day showed : erythrocytes $4,600,000$ per c.mm. haemoglobin 63 per cent.; colour index 0.7; leucocytes 6,800 per c. mm.; polymorphs 77.5 per cent., eosinophils 0.5 per cent., small lymphocytes 11.5 per cent., large lymphocytes 2 per cent., large hyalines 8 per cent., transitional neutrophils 0.5 per cent.

\section{Case H. (Edmonton, London.)}

This case is of interest in that the parrot was a grey African one. It was purchased from a shop in Canden Town on December 24th. It was never well, and, being suspected by the people themselves as the cause of the illness, was taken back to the shop on January 14th. The patient was taken ill about January 4th. She was the only person in the house who looked after the parrot, feeding it and cleaning the cage. There was no mouthto-beak feeding. The patient recovered after a severe illness.

Dcscription of Illncss.

M. S., female, aged 52, was taken really ill on January 11 th, but for about a week previous to this she felt muwcll. On January 11 th she began to shiver uncontrollably. In spite of sitting near the sire, hot drinks, hot-water bottles, and taking to bed, she remained shivering for twenty-four hours. She had a very severe generalized headache, pains all over the body, anorexia, and vague abdominal pains. She had no epistaxis. The bowels were kept open by a daily enema. A troublesome congi with copious purulent grey sputum was present from the first. The sputum was never rusty.

On January $151 \mathrm{~h}$ some moist crepitations and dullness were present in the left posterior axilla and upper lobe. The temperature ranged from $101^{\circ}$ to $103^{\circ} \mathrm{F}$., with slight morning remissions. The respiration rate was about 28 , rarely above 32 , and the pulse rate was about 100 . About this time the patient became drowsy and reluctant to open her eyes. On January 22nd the patient looked ill, weak, and collapsed. Her speech was quite lucid, but it was obviously an effort for her to talk or to move. The chceks were flushed, and herpes was present on the lips. There was no marked respiratory distress. The respiration rate was 30 , the pulse rate 100 , and the temperature $101^{\circ} \mathrm{F}$. The pulse was feeble, easily compressed, and of dicrotic character. There was a systodis murmur at the mitral area. There was no marked dullness, but some crepitations were still present in the left lung. The abdomen was slightly distended, and the spleen was not palpable.

Agglutination tests on January 22nd were completely negative to typhoid, paratyphoid $\mathbf{A}$, and $\boldsymbol{B}$. acrtrycke, but gave a slig...t partial reaction to paratyphoid $B$ (1 in 64$)$.

\section{CASE J. (South Woodford, London.)}

In this case the parrot was a green Amazon, purchased on November 27th from a hawker, who obtained the bird from a sailor at the docks. In the first week of December the bird was obviously ill, with ruffled feathers, diarrhoea, and frothing at the beak; it died on December 12th. The patient looked after the bird, and was himself taken ill on December 17 th. He eventually recovered after a severe illness.

\section{Dcscription of Illness.}

On Deeember 17th A. D., male, aged 60, began to "feel queer," and after a few days of gradually increasing lassitude and chilliness took to bed. Frontal headache, which began gradually, soon became severe. On December 21st he complained of a "woolly" feeling in the ears. He had a severe continuous frontal hesdache, and in addition lancinating neuralgic pain over the top of the cranium, with superficial tenderness. The morning temperature was $101.4^{\circ} \mathrm{F}$. and evening temperature $101.8^{\circ} \mathrm{F}$. The tongue was thickly furred, and there were a few "pinhead "ulcers on the floor of the mouth, with slight general injection of the fauces. On examination nothing abnormal could be detected in the chest or abdomen; the spleen was not palpable. Examination of the central nervous system was normal.

During the following ten days his temperature rose gradually, the morning and evening temperatures showing little difference. The highest temperature recorded was $103.4^{\circ} \mathrm{F}$. on the fourteenth day of his illness. The headache was very persistent. There was slight mental wandering, but a marked feature was apathy and somnolence. He was easily roused, but dozed off again at once.

On January 1st (fifteenth day of illness) a slight cough appeared, and during the next two days a very small quantity of bloodstained sputum was expectorated. Fine crepitations were heard at the base of the right lung. On January 2nd a papular rash, very like measles in appearance, appeared over the extensor surface of both elbows and knees, and over the sacrum. This rash caused no inconvenience, and disappeared in a few days. The chest signs and symptoms had all gone by January 4th, and from this date the temperature fell by lysis and became normal on January 8th (twenty-third day of illness). With the fall in temperature the patient's condition rapidly improved, the somnolence disappeared, and on January 15th he was dressed and able to walk downstairs. Throughout his illness the bowels acted each morning after a dose of magnesia. The pulso rate was never more than 100

Agglutination tests on December 31st were negative to typhoid, paratyphoid $\mathbf{A}$ and $\mathbf{B}, \boldsymbol{B}$. acrtrycke, and $\boldsymbol{B}$. centeritidis.

\section{Case K. (Basingstoke)}

A green Amazon parrot was bought from a London store on November 2nd. It was, however, soon seen to be ill, and was returned on November 26th, dying a few days later. The owner at first used gloves when handling the bird for fear of being bitten. Towards the end the gloves were discarded, and the patient was known to have stroked the parrot's breast, etc. He was taken ill on December 6th, and recovered after a very severe illness, at one stage of which it appeared that he would die.

\section{Description of Illncss.}

C. B., male, aged 50, was taken ill on December 6th, with general malaise and pains in the limbs suggestive of influenza. Within the next fow days he developed a very severe headache, which prevented leep, and an annoying dry cough. He vomited on two occasions. The stools were not abnormal. When seen on Decernber $18 \mathrm{th}$ his temperature was $103^{\circ} \mathrm{F}$., pulse rate 100 , 
and respiration rate 42. His mind was quite clear. He had some red spots on his abdomen not unlike those that occur in typhoid ferer. He had the physical signs of broncho-pncumonia. Agglutination tests at this time were all negative. For many days the patient was so ill that there was little hope of his recovery. After twenty-one days the temperature fell by lysis, and was normal on the twenty-fifth day of the illness. During convalescence thrombosis of the right femoral vein occurred with resulting oedema of the leg. This has gradually improved.

CASE L. (Willesborough, Kent.)

A green Amazon parrot was bought from a large London store about the beginning of December. It was ill from the start, and died on January 12th. The patient was taken ill on December 23rd, and eventually recovered from a very severe illness, during which he nearly died. He was known to have touched the bird and cleaned the cage.

\section{Description of I!lncss.}

T. H., male, aged 45, was taken ill on December 23rd, with hoadache and general malaise. On December $26 t$ h he was seen by his doctor, and found to have a temperature of $104^{\circ} \mathrm{F}$., pulse rato 90 , and respiration rate 26 . He was then complaining of sever headache and backache. His throat was red and his tongue coated, but there were no other physical signs. The next day the patient became rather restless, and was troubled by constipation and abdominal distension. On December 29th S.U.P. 36 was given without. any apprei iable result. On the following day the patient was rather delirious, twitching and plucking at the bedclothes. A dry cough developed, and a few scattered sibilant rhonchi could now be heard in the lungs. The next day (eighth day) a semisiuporose condition was marked, with intermittent complaints of a scvere headache. A further injection of S.U.P. 36 produced no improvement. On January 4th some crepitations were present at the base of both lungs. The abdomen was still markedly distended: The spleen was never palpable. In spite of the paucity of physical signs in the lungs and the absence of any marked pulmonary symptoms the respirations were raised to 35 or 40 during the second week of the illness. On January 10ih the temperature began to fall by lysis, and tho patient gradually recovered from what was a very severe illness.

Agglutination tests to typhoid and paratyphoid $\mathbf{A}$ and $\mathbf{B}$ were negative on the eleventh and sixteenth days of the illness.

\section{Case M. (Norfolk.)}

This case is of interest in that the birds apparently responsible were budgerigars. They were bought in a London shop, and arrived at the patient's house on January 11th, 1930. The next morning both birds scemed in good health, but at 12.30 o'clock one of them was found dead in the cage. The dead bird was handled by the patient, and put away for some days. She then again handled the dead bird in packing it for its dispatch to the London shop where it was bought. The body is said to have been examined by a reterinary surgeon, who said it had died from "inflammation of the bowels from cold." The patient fell ill on January 26th, and recovered after three weeks' illness.

\section{Dcscription of Illncss.}

E. P., female, aged 52, first felt ill on January 26 th, when she complained of very severe headache and "sore scalp." On February 5th her husband noticed that she was short of breath while lying in bed; she got up the next morning and went about her duties, but she felt very ill, and was unable to stand at her work. On February 7th she was first seen by her doctor. Her temperature was $104^{\circ} \mathrm{F}$., and pulse rate 96 . She complained of intense frontal headache, pain in the back, and cough, but had no obvious dyspnoea. The tongue was dry and furred. There was slight diarrhoea. A few rhonchi and crepitations were audible over the right lower lobe. There was slight albuminuria, but no liaematuria:

On February 9th she had a definite epistaxis. She then complained of headache, cough, and abdominal distension. Agglutination tests were negative for typhoid and paratyphoid $A$ and $B$. Blood films showed nothing abnormal. A catheter specimen of urine showed only a eloud of albumin and no deposit.

On February 12th the patient was seen in consultation. On this day her temperature was $103.8^{\circ} \mathrm{F}$., pulse rate 106 , and respiration rate 28. She was pale in colour and mentally quite rational, though at times she had been delirious. The tongue was dry and covered with a brown fur. The heart was clear. The percussion note was impaired; breath sounds were vesicular, and crepitations were audible over the middle and lower lobes of the right lung. The abdomen showed no distension, and the liver and spleen were not palpable. No rose-coloured spots were visible. Agglutination tests were negative for typhoid, paratyphoid $\mathrm{A}$ and $\mathrm{B}$, and $B$. acrtryclie.
A blood count showed red cells 4,000,000 per c.mm.; haemoglobin 80 per cent.; colour index 1.0; there was no apparent increase in the total white cell count; polymorphs 75 per cent., lymphocytes 23 per cent., eosinophils 1 per cent., transitional cells 1 per cent. On February 18th the patient was much better, and her temperature had come down to normal.

\section{CASE N. (London.)}

This is not one of our 27 cases in which there has been definite association with parrots or budgerigars. No contact with any bird could be traced in this case, but the clinical picturo closely resembled that of psittacosis. Although we believe the etiological association with sick parrots to be definitely established with regard to human psittacosis, we nevertheless consider that this case may prove of some interest. Leichtenstern described similar cases, sometimes several in one household, occurring in Cologne in 1898 at the same time as the psittacosis epidemic.

\section{Dcscription of Illness.}

G. C., aged 35, fell ill on January 24th with general malaise, aching in all her limbs, severe headache, and excessive perspiration. The temperature on the first day of the illness was $103.5^{\circ} \mathrm{F}$., pulse rate 84 , and respiration rate 26 . On January 26 th she complained of abdominal pain and vomited a few times. A surgical opinion was sought, but it was decided that there was no definite evidence of an acute abdominal lesion. A slight dry cough was present, and a few crepitations were heard at the right base. The temperature remained between $103^{\circ}$ and $104^{\circ} \mathrm{F}$. during the first week, with very slight morning remissions, the pulse was relatively slow (80), and respirations were not raised. At the end of the week there were signs of consolidation at the right base, respirations began to increase, but there was no sputum. During the second wcek the patient was drowsy and collapsed. The temperature remained high, with occasional remissions to $101^{\circ} \mathrm{F}$., the respirations varied between 28 and 40 to the minute, the pulse remaining slow. When seen on February 6th the patient appeared to be in a typhoid state with muttering delirium. The lung signs were beginning to clear. There had been diarrhoea during the last few days. At the beginning of the third week the temperature began to fall by lysis, and the general condition appeared to improve. On February 12th, however, the patient was still very ill, collapsed, and completely apathetic. Moist sounds were heard at the base of the right lung. She gradually improved during the next week, the temperature, pulse, and respirations remaining normal. On February 20 th she had a relapse, the temperature beginning to rise, and the patient becoming again mentally dull with nocturnal delirium. A trace of albumin was present in an alkaline urine. After $\dot{a}$ week the temperature began to fall again by lysis.

Agglutination tests were negative to typhoid and paratyphoid A and $B$ in the second week of the illness, and these were repeated on February 12th (also with B. aertrycke), with similar negative results.

\section{CLINICAL FEATURES.}

(a) In Previous Epinemics.

Ritter $^{1}$ (1880) described his cases as "pneumotyphus." The onset was like that of an acute fever, with great cxhaustion of the nervous system, high fever, and enlarged spleen. Bronchitis developed in the second week, and progressed to lobular pneumonia. Fpistaxis and herpes occurred in some cases; meteorism, constipation, and fall of temperature by lysis were other features. One patient had roseola. He thought that the incubation period was nine to fourteen days, and that the disease was not contagious from man to man. When the patient recovered, convalescence occurred in the third or fourth week.

Dubief ${ }^{4}$ (1892) gave an account of the clinical picture in the Paris epidemics.

"Its onset is insidious, simulating typhoid fever or influenza. The initial shivering, so characteristic of sharp, straightforward pneumonia, dees not occur except when a late pneumonia sets in as a complication. The real characteristic of this severe infectious malady is the complete prostration in which the sick people are plunged. After a varying period of a typhoidal state there usually appeared a pneumonia, with or without an initial shivering - a pneumonia which often causes the death of the patient. Swelling of the lips may occur where there has been mouth-to-beak feeding."

In 1906, reviewing the past epidemics, Gilbert and Fournier ${ }^{8}$ wrote as follows:

"It is in the nature of a gencral infective malady, allicd to typhoid, in the course of which severe pulmonary complications show themselves. The inoculation period is eight or nine days. Then the signs of invasion commence, analogous to those of typhoid : malaise, collapse, anorexia, intense headache, epistaxis, 
nausca, vomiling, slight diarrhoea, shivering; quinsy, stomatitis with false membrane, and peribuccal oedema have sometimes been noticed. In four or five days or less the temperature reaches $39^{\circ}, 40^{\circ}$, or $41^{\circ}$ C., and maintains itself at this level throughout the illness without pronounced morning recurrences. Great thirst, nausea, and vomiting are present, sometimes incessant; intestinal troubles are often almost absent. The abdomen is somewhat distended, and constipation obstinate. The urine is febrile. The patient is collapsed, of ten without stupor, but often, on the contrary, with profound prostration, accompanied by delirium. The nervous troubles are most pronounced with the appearance of pulmonary complications: general bronchitis with congestion of the bases, pneumonia, broncho-pneumonia, with or without pleurisy. These features are almost constant, and by their severity and gravity dominate the clinical picture. In fact, it is of ten to the pulmonary complications and their effect on the heart and circulation that death is due. In the latter case, after a recrudescence of the fever $\left(41^{\circ} \mathrm{C}\right.$. or more) and some nervous phenomena (hallucinations, carphology, muscular contractions), the patient is seized with extreme dyspnoea, and falls into a terminal coma. Death usually occurs in the second or third week. When recovery is going to take place the symptoms decline in severity after eight, or ten days, and convalescence sets in. In four or five days the temperature has returned to normal, but the convalescence is always lengthy. Benign and attenuated forms have beon noted, especially in children and young ardults, with recovery in a week or so. If one excludes the benign forms the prognosis is always serious. Death follows in a third of the cases. Middle and especially old age, and organic lesions, such as chronic heart disease, nephritis, obesity, and diabetes, are the principal bad factors in the prognosis. The diagnosis of psittacosis would of ten prove difficult without etiological information and the epidemiological character of the illness. Transmission from man to man has been cited by Dujardin-Beaumetz, Dubief, and Nicolle, but this is much more rare than transmission from parrot to man."

Of the Pennsylrania epidémic (1917) McClintock ${ }^{13}$ writes :

"These cases were variously diagnosed as infuenza, pneumonia, and very often as typhoid fever. But in all an element of un certainty was strong. Many of the symptoms of one or all of these diseases were present, but the grouping and degree of intensity of the different symptoms differed from those of any disease so far observed in this community. Although certain cases fitted exactly the accepted symptom-grouping of this disease as a whole, the clinical picture in this epidemic varied more than in those previously described, and the mortality was distinctly lower, not above 5 per cent.

"In this epidemic the incubation period appeared to be about ten days. The duration of the disease varied from one to four wecks. Three groups of cases were easily differentiated. In all three a terrific headache was a common symptom; this was associated with a most profound prostration. The pulse rate was not of ten above 100. The temperature curves were of ten irregular most frequently they simulated those of typhoid fever. The leucocytes when counted were nearly normal in number, and al Widal tests taken were negative. The majority of cases resembled either influenza, with rhinitis, conjunctivitis, and cough; pneumonia with a high sustained fever, but a nearly normal pulse rate or typhoid fever, both with and without a splenic tumour, and without rose spots. Some showed a combination of well-marked symptoms, involving the entire respiratory and gastro-intestinal tracts. In all cases there appeared to be some involvement however slight, of the upper respiratory tract, the lungs, and the gastro-intestinal tract. A peculiar odour, resembling that observed in typhoid, pervaded the surroundings of these patients. The lung signs were very baffling, exhibiting scattered areas of dullness, often wandering, with moist rales, and frequently without any abnormality in the breath sounds. The lung signs rarcly balancen one another, rarely were they typically pueumonic."

In Beddoes's ${ }^{14}$ cases the symptoms were those of pnenmonia, with, however, very marked prostration. The expectoration was slight, and not coloured by blood pigments.

In Gulland's ${ }^{15}$ cases lưng involvement was a marked feature, although the cough was slight and sputum negligible. In the first case the illness starterl with a sudden pain in the side, and in the second case with a rigor. From the latter case $10 \mathrm{oz}$. of clear sterile fluid was withdrawn from the pleural cavity. The temperature rose in step fashion and fell by lysis. A depressed mental state was present in both cases.

Stolkind's ${ }^{16}$ second case was fatal, and at necropsy pneumonia of the right lung and lower half of the left lung was found.

In Thomson's ${ }^{\mathbf{1 7}}$ cases (first series) the development of an enlarged, painful parotid gland occurred in one patient. Of his four cases, two were fatal.

\section{(b) Present Series.}

The symptomatology and physical signs in our series of cases corresponded closely with the classical description of Gilbert and Fournier. ${ }^{8}$ In many respects there was a marked resemblance to typhoid fever, but pulmonary involvement of varying degree occurred in every case. The illness usually lasted two to three weeks, during which time the patient's condition was often critical.

\section{Incubation Period.}

In eight cases the incubation period could be deternived with some degree of certainty. It varied between eight and thirteen davs. This is in agreement with the observations of Ritter, 1880 (nine to fourteen days), Dubief, ${ }^{4} 1893$ (nine days), Gilbert and Fournier, ${ }^{6} 1896$ (eight to nine days), and Mc('lintock $\mathrm{k}^{13}$ of Pennsylvania, 1917 (seren to twelve days).

\section{Onset.}

The onset was sudden in most cases, the patient taking to bed within a few hours of the initial symptoms.- In a few instances, however, a mild degree of malaise occurred for some days, during which time the patient continued with his normal occupation.

The initial symptoms were usually headache and malaise. These were often associated with, or soon followed by, shivering, generalized pains in all the limbs, backache, abdominal pain, anorexia, nausea, vomiting, sore throat, sweating, and epistaxis. Conjunctivitis occurred but rarely. The headache was usually very severe, and was not ameliorated to any extent by analgesies. It was most commonly situated in the frontal region, but was sometimes parietal, occipital, or generalized. One patient described her headache as "throbbing and sore, as if someone was beating or scraping the top of my head." Increasing in severity during the first few days, the headache persisted for about ten days and then tended to disappear.

The shivering attacks or rigors were not constant in their time of onset. Sometimes they occurred as an initial or early symptom, whereas in other cases they coincided with the beginning of pulmonary involvement (as described by Dubief). In one case rigors occurred on the fourth, fifth, and tenth dars. Although sometimes slight and of short duration, in other cases they were very severe and lasted for twenty-four hours.

Sore throats were not infrequent, the fauces and soft palate being red and sometimes covered by a rellowish exudate. In only one case was the classical sign of peribuecal oedema observed, and that occurred in a patient who was actually bitten on the tongue by a parrot. Sordes of the lips and herpes labialis were present in some cases.

Epistaxis occurred in six cases, usually within the first few days, and was often profuse. In one case it started on the fourth day and recurred every day in large amounts until the ninth day.

Rose spots were observed in five cases, usually appearing about the end of the first week. Their characteristics are given with the detailed description of the cases.

\section{Respiratory System.}

The lungs were involved in all cases. A cough developed usually towards the end of the first week, although in some cases it was an initial symptom, and in others it lid not appear before the seeond week. Usually the cough was a dry one, but in several of the cases, particularly those of Group B, there was a considerable quantity of muco-purulent sputum. In only one case was there typical rusty sputum, and that occurred in the late stages of a fatal cases. The cough was often troublesome and intractable, paroxysms of coughing shaking the whole body, aggravating the headache, preventing sleep, and leaving the patient very exhausted.

In spite of pulmonary symptoms and signs the respirations were usually not markedly quickened, although in fatal cases, and in some that recovered, respirations were raised to 40 or more a minute.

The signs in the lungs were variable. As a rule they began with a few moist sounds at one or both bases. In some cases there rere, in addition, rhonchi scattered 
throughout the lungs. The crepitations usually appeared about the sixth to tenth day, and gradually increased in number. During the second week a patch of consolidation not infrequently developed near the angle of one scapula. In some cases this area appeared to spread so as to involve the whole of one lower lobe, or other small areas of consolidation might be present at the bases of both lungs. The physical signs were occasionally those of a wandering pneumonia. In many cases the signs did not progress beyond the presence of moist sounds, and in two cases the pulmonary signs and symptoms were of the slightest. In one fatal case there was a slightly turbid pleural effusion and in another a pleural rub was heard. The crepitations at the bases of the lungs often persisted for several days after the temperature was normal. Cranosis was present in those cases where the lungs were extremely involved, especially in the fatal cases.

\section{Tervous System.}

Photophobia was noted in several cases as an early symptom, one of the patients stating that she saw double when looking at objects in bright light. Some of the patients insisted on the blinds being drawn, and others wore eveshades. A trphoid-like state developed towards the end of the first week. The patients usually lay quite still in bed in a collapsed immobile condition. They were often very sleepy after the first few days, finding difficulty in keeping their eyes open; later they became stuporose and even semi-conscious, some of the fatal cases falling into deep coma. They appeared to be quite oblivlous to their surroundings, of ten failed to recognize their friends, were roused with varying degrees of difficulty, and soon lapsed into their previous state. Alternating with periods of somnolence there sometimes occurred phases of great excitement and restlessness. One patient became very aggressive and stunggled to get out bed. Another, in a nursing home, actually left her bed and rang the bell without knowing why she did so. Delirium was common, and worse at night. Two patients complained that they unsuccessfully tried to keep awake because if they fell asleep for a few minutes they awoke muttering nonsense. Disorientation of time and place frequently occurred.

Examination was greatly resented by some, whereas others were completely uninterested in what was happening. The patients often remained in a collapsed and stuporose condition for several days after the temperature had fallen to normal. An interesting feature was the complete failure of many of the patients to remember the greater part of their illness.

\section{Gastro-intestinal stymptoms.}

Anorexia and nausea were frequent early symptoms. In some cases vomiting was present, and although usually occurring but once or twice, was sometimes incessant. Initial abdominal pain occurred in a few cases, the doctor in two instances considering the possibility of appendicitis.

Constipation was present, and troublesome, in the majority of the cases, the abdomen being very distended. Meteorism was relieved by turpentine enemata and the passage of flatus. In a few cases diarrhoea occurred at some period during the illness, but only for a few days. There were no signs of intestinal haemorrhage or of perforation. The spleen was not palpable in any of our cases.

\section{Cardio-rascular System.}

In the majority of cases the rate of the pulse was markedly slow in relation to the temperature. Thus with a temperature of $1030 \mathrm{~F}$. the pulse was often less than 100. In those with extensive involvement of the lungs and in all fatal cases the pulse became rapid and feeble. There were no signs of importance in the heart, although a systolic murmur might be present in the apical region. In two cases thrombosis of the femoral vein occurred during convalescence.

\section{Pyrexia.}

The temperature was generally very high (about $103^{\circ} \mathrm{F}$.) from the outset. There was usually no definite evidence of a step-ladder rise as in typhoid. The temperature was maintained at a high level for about two weeks, when it usually fell by lysis. In many cases there was hardly any remission of temperature during the mornings, but in others the pyrexia was of the swinging variety with morning remissions.

In the convalescence period the temperature was often subnornal (970 F.). In the fatal cases the temperature tended to remain high throughout. Convalescence was often slow and tedious. In a few cases there were definite relapses similar to those occurring in typhoid fever.

\section{Diagnosis.}

A typhoid-like illness, with pulmonary involvement and negative agglutinations, is very suggestive of psittacosis, especially if there is a clear history of association with a sick parrot.

\section{Prognosis.}

The mortality in this series was approximately 20 per cent. The ages of those that died were $60,53,52,30$, and 18. One of the chief factors in the prognosis appears to be the extent of pulmonary involvement and associated socondary infection. In all the fatal cases there was much respiratory distress, cyanosis, and profound toxaemia. These features were especially marked in the Barking group B, where 3 out of 5 died.

\section{Mode of Infeotion.}

Of our 27 cases, 25 were apparently caused by green Amazon parrots from South America. In 23 cases the birds were very recently imported, and were more or less ill from the start. In two cases the parrot concerned had been in the country for a few months.

Of the two grey African parrots, one was recently imported and was obviously sick. The other had been in this country for eight months, was apparently in good health, and must be regarded as a carrier of the disease. In this case the contact necessary for transmission of the disease had to be niost intimate-biting of the patient's tongue. In those cases where the bird was itself obviously ill, contact was often of the slightest, and in one case, where the patient merely sat in the room from which the dead bird had recently been removed, it would seem that the infeating agent had been disseminated throughout the room.

Man-to-Man Infection.

We consider this the probable mode of infection in two of our cases. Dujardin-Beaumetz ${ }^{4}$ (1892) and Nicolle ${ }^{20}$ (1898) gave some evidence of man-to-man infection, the latter citing the case of a nurse. Banti and others, ${ }^{21}$ in describing the Florence epidemic of 1894-95, state: "As for contagion, direct carrying from person to person, there were incontestable if rare examples." Leichtenstern $^{11}$ describes a definite case in Cologne (1898) where the patient had been in contact with the parrot at another house, and the nurse, who apparently contracted the disease from the patient, had never been in the same house as the parrot. Other cases (for example, medical attendant) have come to our knowledge but are not in our series of cases. Man-to-man infection must be regarded a:s a rare but possible mode of contracting psittacosis.

\section{BACTERIOLOGY AND.SEROLOGY.}

Ritter ${ }^{1}$ (1880) reports that some of the parrots concerned in the epidemic died and the remainder were killed. All the birds were examinced after death by Professor Eberth with negative findings.

In 1883 Wolff $^{22}$ examined the bodies of twelve grey parrots from the Guinea Coast with a view to explaining the immense mortality in parrots brought thence to Germany, and found micrococci in great numbers. Eberth ${ }^{23}$ had similar findings with a grey parrot.

In 1892 Nocard $^{4}$ isolated a bacillus (B. psittacosis) from a parrot. It is of interest to note that Nocard was unable to secure any of the birds that caused the Paris epidemic. He writes:

"In spite of my efforts I have not been able to procure, dead or alive, one of the many sick parrots imported by Dubois and Marion, and I do not know that others have been more fortunate; at least no one has published chirical observations or the results 
of a complete and methodical necropsy on a single one of these parrots. I have been able, howcver, to make some interesting researches, thanks to the kindness of $M$. Besançon, who has been good cnough to put at my disposal a large packet of wings belonging to parrots that died on the voyage from Buenos Aires to Havre. .. Before throwing the corpses ints the sea Marion deprived them of their wings, which he carefully packed after having dried them."

Nocard examined them four months after this, and obtained from the marrow in pure culture an organism he described as follows:

"A short bacterium, rather thick, with rounded extremities, both acrobic and anaerobic, extremely motile; the bacterium develops rapidly over the greater part of the media. solid or liquid, used in microbiology, provided that the reaction of the medium is neutral or slightly alkaline; it is Gram-negative, does not liquef $\mathrm{y}$ gelatin, does not ferment lactose, does not coagulate milk. It is pathogenic for the pigeon, fowl, mouse, rabbit, and guinea-pig."

In $18 \varepsilon 6$ Gilbert and Fournier ${ }^{7}$ secured a parrot that had died of diarrhoea, and obtained Nocard's bacillus from the spleen, bone marrow, and intestine. In the case of $\mathbf{M}$. and Mme $\mathbf{X}$, who died of psittacosis, Gilbert and Fournier examined the sputum, and also the blood obtained by pricking the finger. The sputum contained pneumococci and streptococci, but not Nocard's bacillus. Blood culture was sterile. Blood culture (from the vein) in two other cases was also negative. In one of these cases pleural fluid and splenic puncture three days bofore death also gave sterile cultures. Blood from the heart of this patient (at necropsy) riclded a bacillus identical with that of Nocard. Gilbert and Fournier state that the bacillus of Nocard resembles that of Eberth, but it is clearly distinguished by the appearance of the culture on gelatin and on potato, and especially by its extreme virulence to laboratory animals, which are killed in twenty-four to forty-eight hours. Parrots may die ten to twelve hours after subcutaneous injection of two drops of broth culture. In La Presse Médicale, however, Gilbert and Fournier ${ }^{6}$ wrote as follows:

"The morphology and biological propertics of Nocard's bacillus enable us to suggest that this micro-organism is no other than a coli bacillus normally inhabiting the intestine of parrots and acquiring under unknown influences pathological properties. We have found in the intestines of normal parrots special varietics of para-coli bacilli, some of which approximate in character to the bacillus of Nocard."

They also noted that trphoid serum produced small agglutinations with Nocard's bacillus, but to a very much less degree than with typhoid bacillus. 'The serum of two patients, ill with psittacosis, did not prorluce any agglutination with 3 . psittacosis obtained from the parrots, or from the heart's blood of another fatal (ase (previously recorded). The patients were only in the fifth day of their illness.

In 1897 Sicards $^{5}$ examined two parrots that were the cause of a small epidemic, and had dien. In the case of one of these birds he obtained 3 . psittacosis from the heart's blood and bone marrow, but it is interesting to note that he was unable to obtain the bacillus either from the blood or from the organs of the second parrot. He was equally unsuccessful with some small exotic birds that had been in contact with the parrots and that had died. As regards man, Sicard" had negative results from "the numerous and frequently repeated cultures made at the height of the fever and in the convalescent period, from the blood of the arm vein, from the spleen, from the lung, or from the urine and faeces of the very ill patients taken into hospital."'

Sicard $^{5}$ also investigated the power of agglutination in man.

"The serum of the hospital patient was examined during the development of the illness, on the fifth day of the illness, then every second day, and during the convaleseent period every four days. The serum of the other four patients was only taken twice, once during the period of the illness and once during convalescence. The suspected serum behaved towards $B$. psittacosis in the same manner as that of normal people, or of patients with other illnesscs. There was. produced under the influence of any human serum a physiological agglutination of this bacillus.
This agglutination always exists at 1 in 5 , is able to continue at 1 in 10 , and in some cases at 1 in 20 , and presents slight variations accordine to the culture employed. Those of $\mathbf{M}$. Nocard and our own always appeared to agglutinate a little more than those of MM. Gilbert and Fournier. This agglutination, which occurs with a serum kept for some time, is often defective with fresh serum, and is then replaced totally, or in part, by a transformation into granules, without complete bacteriolysis."

Sicard $^{5}$ then investigated the bactericidal properties of the suspected serum with negative results.

"Tested with fourteen human serums, precipitation of bacilli occurred at the bottom of the tube. Micrascopic examination showed numerous masses, of ten in long and flexible chains. The vitality of the hacilli was preserved, as well as their virulence, as was shown after twenty-four hours in agar by inoculation into mice. From the preventive point of view we have equally been unable to establish a difference of action between the suspected serum and other serums, which were injected into mice and sparrows twenty-four hours before their inoculation to $B$. psittacosis."

\section{Nicolle ${ }^{9}$ in 1898 reports as follows:}

"We have not been able, in spite of all our efiorts, to isolate the pathogenic microbe from the different produsts which have been sent us: blood of three patients, faeces of two, sputum of one. The necropsy of the parrot also gave negative results. In the case of one patient, atlacked with a fatal form of the disease, the serum taken on the eighth day agglutinated B. psittacosis 1 in 50, and on the ninth day (when the patient was dying) the agglutinating power reached 1 in 60 . The same serum has twice shown activity of 1 in 30 to tvphoid bacilli, but no action on $B$. coli. The patient had never had typhoid fever.

"In the case of a sccond patient, severely attacked, but who recovered, the serum taken on the sixth day was without action on Nocard's bacillus, typhoid bacillus, and Bucillus coli; on the eleventh day it agglutinated $B$. psittcicosis 1 in 10 , but remained inactive towards the two other microbes. The blood of a third mild case, examined on the sixth day, had no agglutinating power. Parrot's serum, obtained on the fifteenth day after its recovery, also gave negative results."

Gilbert and Fournier, ${ }^{8}$ reviewing the situation in 1906, state

"M. Nicolle has shown that the serum diagnosis of psittacosis is possible, the agglutinating power being relatively raised in one of his cases ( 1 in 50, 1 in 60) and feeble in another ( 1 in 10). But. the agglutinating power is often wanting (Gilbert and Fournier, Sicard). . . . Do there exist other forms of psittacosis o. other infective maladies of parrots transmissible to man and not having the bacillus of Nocard as pathogenic agent? This is quite possible. The bacillus of Nocard could not in some cases be recovered from the bodies of parrots which had apparent!y been the focus of spread of small limited epidemics; but these facts are still badly defined, clinically and bacteriologically; it suffices to note them."

In 1904 Vickery and Richardson ${ }^{12}$ recorded that the serum of their patients was negative to typhoid and paratrphoid bacilli, and to a streptococcus recovered from the spleen of the parrot. Apart from the latter, which they regarded as a contamination, all cultures frem the organs of the dead parrot were negative. No bacteriological or serological findings are reported in the cases of Beddoes (1914), Gulland (1924), or Stolkind (1927).

In 1917, when studying an epidemic in Pennsylvania, McClintock ${ }^{13}$ found a variety of organisms, and suggested a pleomorphic nature of $B$. psittacosis. In 1920 Marrian Perry ${ }^{21}$ obtained $B$. psittacosis from a grey touracon that had died, and by absorption and agglutination tests found that 73. psittacosis was identieal with 73 . aertrycke of the "Mutton" type. He quotes Bainbridye, who came to a similar conclusion.

Thomson ${ }^{17}$ (1929) records serological and bacteriological findings in one of his cases. The Widal test was positive to paratyphoid B 1 in 1,000. In the course of the illness the right parotid gland became swollen and painful, and a small quantity of blood-stained fluid was aspirated from it and culture media inoculated. Cultures gave a bacillus which was first Gram-positive, but after forty-eight hours' growth in vitro became completely Gram-negative. Thomson observes that the bacteriological report, " although it does not conform in every detail with some of the published accounts of $B$. psittacosis, nevertheless shows that it belongs to the same group of organisms, individual strains of which 
are known to rary considerably in their behaviour in the laboratory." Thomson, however, does not regard the identity of the bacillus as established.

In view of the classical conceptions of the etiology of psittacosis, we approached our first case from the point of view of obtaining positive agglutination tests with 13. psittacosis, and perhaps isolating the bacillus. Our results were completely negative, even after necropsy. This appeared to throw doubt on the diagnosis and to indure a sceptical attitude as to the question of parrot infection. A. close study of all the available literature, however, brought out several important points: (1) There was the strongest cireumstantial evidence in favour of paryots being the cause of psittacosis. (2) Several able investigators, Sicard ${ }^{5}$ among others, had failed to obtain any evidence of positive agglutinations with typhoid, paratyphoid, and psittarcosis bacilli in undoubted cases of the disease. The titre of agglutination in some of the Paris cases was of such an order as to have little or no significance. (3) Throughout half a century the alleged causative organism, $B$. psittacosis, had been isolated from a human being in only one rase, and that at necropsy. This was done by Gilbert and Fournier, 78 who, when reviewing the wholc subject at a later date $(1806)$, themselves began to doubt its etiological significance. (4) The classical clinical descriptions corresponded so closely with our first case and the second member of this group (whom we had subsequently visited) that the diagnosis of psittacosis seemed without doubt.

It was in an endeavour to fit all these facts together that we conceived of the possible virus origin of the disease, and we were fortunate in securing the collaboration of Dr. S. P. Badson and Dr. G.P. Western in investigating this point. Many of the results of the experimental inrestigations have already been jublished, ${ }^{25}$ and we shall therefore not describe them in this paper. In brief, it may be stated that a filterable virus was isolated from parrots which had died of psittacosis and which had been responsible for cases of the disease in man. Further, ritrated blood from human cases, although apparently sterile when tested culturally, produced the discase in every instance when inoculated into budgerignrs. It lias been seen from the detailed notes of our cases that negative blood cultures and negative agglutinations have been found in nearly all of them. It is true that the close similarity between many of the clinical features of psittacosis and those of typhoid fever might by analogy suggest a bacillary origin for the former, but a consideration of this question opens up a very wide field of inquiry. The London Hospital investigations offer strong evidence in favour of the rirus origin of psittacosis, although this does not exclude the possibility of secondary infeetion with other organisms.

\section{PATHOLOGTCAL REPORTS BY PROFESSOR} H. M. TURNBULL.

\section{Grotip E, Case 1.}

Summary of Findings.-Thrombosis of pulmonary arteries. Haemorrhagic pneurnonia. Septicaemia. Slight nuco-purulent bronchitis. Diffluent, red septic spleen; iron pigment in spleen. Parenchymatous degeneration and post-mortem staining of myocardium, liver, and kidneys. Oedema of kidneys. Iron pigmentation of coeliac gland. Proteolysis and lipolysis of very adipose pancreas. Great central softening of suprarenal bodies. Emphysema of lungs; quiescent tuberculosis; pinhead fibro-caseous nodule in apex of upper lobe of right lung; pinhead calcareous nodule in lymphatic gland of tracheal bifurcation. Eight pigment calculi (largest 1.4 by 0.7 by $0.7 \mathrm{~cm}$.) in gall-bladder. Foramen oicle closed. Moderate general atheroma. Numerous chylecysts in submucosa of jejunum; Peyer's patches small and inconspicuous. Fibrous obliteration of terminal $1.5 \mathrm{~cm}$. of $11 \mathrm{~cm}$. appendix. Sessile polyp $(0.25 \mathrm{~cm}$. diameter) in transverse colon. A few small (largest $0.15 \mathrm{~cm}$.$) internal haeniorrhoids. Stout, grey-hairer,$ Nell-developed man. Examination of brain not permitted.

Heights: Body, 82 kilograms (length 1.68 metres); liver, $1,417.5$ grams; heart, 320 grans; kidneys, 290.6 grams; spleen, 177.2 grams; pancreas, 126.2 grams; supiarenal bodies, 11.2 grams.

\section{Macroscopic Examination.}

The necropsy was performed by Dr. A. B. Bratton. The bredy had not been placed in the freezing chambers, and there was moderate post-mortem degeneration throughout. A portion of friable striated thrombus, $3 \mathrm{~cm}$. long and $1 \mathrm{~cm}$. in diameter, lay free in the pulmonary artery in the hilum of the upper lobe of the right lung; a fragment of similar clot, $2.5 \mathrm{~cm}$. long and $0.7 \mathrm{~cm}$. in diameter, lay in the pulmonary artery to the upper lobe of the left lung. There was no ante-mortem thrombus in the large veins of the neck, chest, and abdomen; incision of the limbs was purposely a voided, but the content of the subclavian and femoral veins was expressed and consisted of fluid blood. The most striking abnormality was the condition of the lungs. There was no free fluid in the pleural saes. The lungs were roluminous and showed the characteristic appearances of hypertrophic emphysema. A thin layer of fibrin covered the lower part of the upper lobe of the left lung, and a layer of fibrin containing numerous red clots lay on the anterior surface of the lower lobe. The lower third to one-half of the onter surface of the upper lobe of the left lung, from a little below the apex to the tip of the lingula, was swollen and dark purple. It felt boggy and gave slight crepitation. The cut surface was deep red, and very slightly granular; blood and a few bubl,les of air were alone expressed. On the cut surface of the rest of the upper lobe of the left lung were a few small areas of similar appearance, and yellow slime was expressed from some bronchi. The anterior surface of the lower lobe of the le $\mathrm{ft}$ lung was depressed and dark red, while the angle between the anterior and diaphragmatic surfaces was replaced by a thin. flabby, airless fringe. On section a smooth, deep red, largely airless zone $(0.5 \mathrm{~cm}$. deep) lay under the depression, and the fringe had a similar appearance. On pressure, yellow slime escaped from some of the bronchi in the depressed area, and in the remainder of the left lower lobe. Yellow slime was expressed from some bronchi in the right middle lobe. The lower lobe of the right lung resembled externally the lower part of the left upper lobe, being swollen and dark purple. The upper part felt less solid than the lower, and crepitated. The cut surface of the whole lobe was deep red. The upper. part was very slightly granular, the lower part was more homogeneous and more granular, but the granulation was not. conspicuous. The cut surface recalled that of the haemolytic streptococcal pneumonia which was associated with influenza in 1918. Yellow slime was expressed from brouchi in the antero-inferior angle alone. A portion was removed from the posterior part of this lobe for bacteriological examination liv Dr. G. T. Western. The abnormalities in other organs have been indicated in the summary. No cvidence of inflamination could be detected in the intestines.

\section{Microscopic Fxamination.}

Portions were removed for microscopic examination from the swollen luwer border and lingula of the upper lobe of the left lung, the upper and lower parts of the swollem lower lobe of the right lung, the collapscd zone bentaith the pleura of the anterior surface of the lower lube of the left lung, the spleen, the pancreas, and the pigmented cocliar gland.

The Lungs.-In the upper part of the lover lobe of the right lung all the vessels are greatly engorged. The walls of the bronchioles are intensely injected and are infiltrated with large mononuclear leucocytes, histiocytes, large and small lymphocytes, and a few neutrophil lewcocytes. The lumen of one contains red corpuscles, a few desquamated epithelial (e)lis. neutrophil leucocytes, and large mononuclear leucocytes. The others have an empty lumen, and have lost their epithelium. The respiratory bronchioles, alveolar passages, and infundibula almost all contain inflammatory exudate, but seldom appear completely filled by it. The few that are empty are difated. Most contain neutrophil and large mononuclear leucocvtes, reil ccrpuscles, and desquamated-epithelium. Some contain also a little bubbly coagulated albumin or a few threads of fillin. In one area red corpuscles are very numerous, and here fibrinous and serous exudate are much more abundant, while leucocrtes are relatively scanty. Changes in the epithelial lining of the affected air spaces are conspicuous. The epithelial cells are greatly enlarged, and have an abundant spongy basophil cytoplasm; the nuclear membrane, close net of (hiromatin threads, and large nodes are brightly stained. Several show karyokinetic figures. Small heaps of large cubical and rounded epithelial cells frequently lie upon the muscular wall of the respiratory bronchioles, while ribbons of large spindle cells lie upon or close to alveolar walls. Other epithelial cells, lave been desquamated and are rounded. The pleura is swolten by oedema and contains some haemorrhages.

In the lingula of the upprr lobe of the left lung the in filtration of the walls of the bronchioles is greater and contains 
more numerous neutrophil leucocytes. In some a deep zone of neutrophil and large mononuclear leucocytes raises the epithelial lining as a continuous sheet, in others the raised sheet is broken, and leucocytes have reached the lumen. The centres of the lumina are usually. empty or nearly empty; one contains coagulated serum and a few leucocytes. The respiratory bronchioles, alveolar passages, and infundibula contain an infiltrate which in general resembles that in the previous section. The cellular infiltrate is, however. more abundant, filling and distending the spaces, and bubbly coagulated exudate is more frequent. The pulmonary arteries are greatly engorged, but are not thrombosed.

In the posterior part of the lower border of the upper lobe of the left lung a large bronchiole has great haemorrhage in its wall, the epithelium consists of a layer of flattened cctls; the centre of the lumen is occupied by air, and the periphery by leucocytes, red corpuscles, necrosed cells, coagulated albamin, and a few filaments of fibrin. The respiratory bronchioles and alveolar passages contain an exudate similar to that in the infundibula, but many are greatly distended by air, the exudate being confined to the periphery of the lumen. The exudate is more abundant than in previous sections and distends the air spaces more. It consists mostly of coagulated albumin, but in places of fibrin. Red corpuscles are very numerous. They are more numerous in the fibrinous than in the serous exudate; groups of alveoli are crammed with red corpuscles. The cells seen in previous sections are present, but they form a relatively insignificant part of the exudate. Further, most of them are very degenerate, or are completely necrosed and represented by cytoplasmic spheres; some well-stained neutrophil leucocytes are, however, always present.

Hyaline thrombi are frequent in the engorged capillaries of the alveolar walls. Hyaline thrombus also lines or fills several small pulmonary arteries. Some larger pulmonary arteries show a peripheral layer of degenerate leucocytes; a few are flled with white thrombus. The pleura is congested, slightly infiltrated, and covered by a layer of fibrin.

In the lower part of the lower lobe of the right lung there are still respiratory bronchioles and alveolar passages distended by air, and occasional groups of alveoli which contain little or no exudate. The condition is very similar to that in the previous section, but fibrin containing many red corpuscles is now the predominant form of exudate, many alveoli are filled with red corpuscles, most of the alveolar capillaries contain hyaline thrombus, hyaline thrombus fills a great number of the smaller pulmonary arteries, and many large pulmonary arteries are occluded by white or mixed thrombus. Large bronchioles are lined by one or two layers of flattened spindle epithelial cells; and are filled with fibrin; ghosts of necrosed cells, a few red corpuscles, and scattered neutrophil leucocytes. There is great oedema of the pleura.

In the anterior surface of the lower lobe of the left lung there is a subpleural zone of collapse, which contains a few emphysematous areas. Beneath this there are small areas of collapse in a general emphysema. The tissue throughout is intensely engorged. In the subpleural zone there is an area in which the collapsed alveoli contain a few red cells and leucocytes, while a respiratory bronchiole shows a few leucocytes beneath its epithelium, and a few leucocytes and red corpuseles in the periphery of its lumen. The feature of this section is the presence within bronchioles and respiratory bronchioles of desquamated epithelium, a few large mononuclear and neutrophil leucocytes, and masses of bacteria. The bacteria are Gram-positive, and in less number negative, streptococci and staphylococci, and Gram-positive, long, stout bacilli. In the other portians of the lungs no organisms were found in sections stained with dilute carbol-fuchsin or by the WeigertGram method with neutral red.

The spleen was so diffluent at necropsy that the tissue in the microscopic sections is split into small fragments. It is impossible to differentiate the capillary veins from the pulp strands. The organ is engorged and infiltrated. Neutrophil leucocytes are numerous, but the feature of the infiltration is the great number of large mononuclear cells with deeply basophil cytoplasm (Unna-Pappenheim stain) and conspicuous nodes and nucleoli. Somie of these cells have the clock-face nucleus of . plasma cells, others contain karyokinetic figures. 'There is much haemosiderin, chiefly within cells. No microorganisms were found in a section stained with dilute carbolfuchisin.

The pancreas is very adipose. There is very extensive digestion of the glandular tissue and islands; and much lipolysis of the adjacent adipose tissue. The ducts contain digested desquamated epithelium, and sometimes also a little mucous coagulum. There is no cellular infiltration.

The cocliac gland shows areas in the adenoid tissue in which the walls of vessels have undergone great hyaline collagenous swelling, recent necrosis in the centres of many cortical nodules, and great sinus-catarrh. Most of the desquamated cells in the sinuses are large and necrosed. "Many contain fine granules of a brown pigment that does not give an iron reaction, others contain large grains of haemosiderin. The sinuses also contain red corpuscles and numerous extra cellular isctropic particles of brown-yellow haemosiderin, of which most are large, and fusiform or spherical.

\section{Timarlis}

The changes found at necropsy were those of a general infection, or bacteriaenia, associated with a peculiar inflammation of the lung.s. No bacteria were found microscopically except numerous streptococci, staphylococci, and Gram-positive bacilli within bronchioles in one section of the lung.

The naked-eye and microscopic examinations showed that this bronchitis very rarely affected the portions of lung involved in the pneumonia. There can be no doubt that it was a terminal and independent muco-purulent bronchitis. The peculiar inflammation of the lung involved bronchioles, but it had not the appearance of a pneumonia secondary to bronchitis-that is to say, a broncho-pneumonia. The descriptions of the portions of lung examined microscopically have been set in the order of apparently progressive stages in the intlammation. Briefly, an intense engorgement, proliferation and desquamation of epithelium, leucocytic infiltration, and slight haemorrhage were followed by increasing haenorrhage, abundant serous and later fibrinous exudate, progressive degeneration and death of the earlier infiltrating cells, and an increasing thrombosis of capilla!ies, and small and large pulmonary arteries. The extent of the thrombosis in the severest expression, apparently the last stage, of the inflammation was most remarkable.

The portions of thrombi found in the pulmonary arteries in the hila of the upper lobes of the right and left lung had doubtless been formed within pulmonary arteries; no thrombosis was found in large veins of the systemic circulation.

The amount of haemosiderin in the spleen, and particularly in the coeliac gland, gave evidence of much destruction of haemoglobin, but laked red corpuscles were not seen. The characteristic of the inflammation of the spleen was the infiltration with large cells of lymphoblastic type.

The digestion of the pancreas, like the central softening of the suprarenal bodies, was doubtless due to autolysis in a severely infected cadaver that had not been placed in the freezing chambers. The preservation of the tissues in general, however, was shown by the microscope to be good, and much better than was expected from the appearance at necropsy.

\section{Group B. Cases 1, 2, and 4}

The microscopic examination of the material from these three cases has not yet been made. The necropsies were in general closely similar to that of Group $\mathbf{E}$, Case 1. Terminal heart failure was shown by conyestion and oedema of the liver and kidneys, and in Case 1 by oedema of the legs. Septicaemia was indicated by parenchymatous degeneration of the myocardium, liver, and kidneys, and by increased cellularity of the pulp of the spleen. The severest changes were in the lungs. $\boldsymbol{\Lambda}$ new feature was found by Dr. W. W. Woods in Case 2 in the form of focal areas of degeneration, haemorrhage, and rupture in the rectus abdominis muscle; and in Case $4 \mathrm{Dr}$. A. B. Bratton found focal haemorrhages in the rectus abdominis and the gluteus maximus.

Lungs.- The changes in the lungs were most advanced in Case 1. In the left lung the lower lobe and lower third of the upper lobe were conspicuously swollen and purple, while the remainder of the upper lobe was slightly swollen. The lower half of the lower lobe and the lingula of the upper lobe felt like liver, and on section showed an even, finely granular, pink cut surface. On pressure, very abundant frothy fluid exuded from the bronchioles. Excised portions just sank in water. Similar changes will be referred to as red hepatization. The remainder of the left lung felt boggy, with focal areas of firmer consistence. 
When freshly cut the surface was rery moist, or ran with water, showed light speckles of aeration in a few small areas and faint granulation in larger patches, but for the most part appeared homogeneous, somewhat gelatinous, and grey or pink. On pressure a great deal of frothy fluid and a considerable quantity of blood exuded. Fxcised portions floated in water. This change will be referred to as partial infiltration and oedema. In the right lung the posterior two-thirds of the upper lobe and the posterosuperior three-quarters of the lower lobe were swollen, and occupied by red hepatization. Between the hepatization in the lower lobe and the visceral pleura was a zone of lung which showed a few small speckled areas of aeration, but was for the most part airless, smooth, red, and collapsed. The remainder of the right lung showed chronic vesicular emplysema. Occasionally there was a little grey mucus in the frothy fluid which exuded from the bronchioles. The pulmonary arteries in the lower lobe of the left lung at a little distance from the hilum contained red thrombus.

In Case 2 the anterior fifth of the left upper lobe, the right middle lobe, and the anterior quarter of the right upper lobe showed vesicular distension and great inter-itial emphysema. The lower fringe of the left lower lobe was partly speckled by aeration, partly collapsed, and congested. The lower quarter of the left lower lobe felt shotty, and on section showed pinhead nodules of peribronchiolitic consolidation in an injected, collapsed ground. The remainder of both lungs was swollen and occupied by partial infiltration and oedema. The scattered granular areas in this partial infiltration measured in diameter about $0.7 \mathrm{~cm}$. in the upper and lower lobes of the left lung, and $1 \mathrm{~cm}$. in the upper lobe of the right lung; in the lower lobe of the right lung was an area of red hepatization $3 \mathrm{~cm}$. in diameter. The frothy fluid which exuded from the bronchioles was everywhere slightly clouded; in the upper lobe of the right lung it contained grey mucus, in the lower lobe of the right lung it contained vellow muco-pus. The mucosa of the bronchi and trachea was rovered with blood-stained, slightly purulent mucus. One or two pulmonary arteries in the lowe $i$ lobe of the left lung contained red thrombus near their terminations.

In Case 4 there was red hepatization in the apex, and in the lower border of the left upper lobe to within $5 \mathrm{~cm}$. of the tip of the lingula; and there was partial infiltration and oedema in the remainder of the posterior two-thirds of the left upper lobe. Red hepatization cccupied also the posterior third of the middle lobe of the right lung. Congestion and collapse affected a few lobules in the lingula, and a subpleural zone in the lower part of the posterion border of the lower lobe of each lung. The remainder of the lungs showed chronic resicular smphysema. Milky mucus came from the bronchioles in the collapsed lobules in the lingula, and grey mucus from some of the bronchioles in the area of hepatization in the right widdle lobe, the collapsed area in the left lower lobe, and the acrated portions of both lungs. The mucosa of the bronchi and trachea was covered with frothy mucus flecked with pus.

The largest amount of pleural effusion was an ounce in Case 2. A thin layer of fibrin lay upou the upper lobe of the left lung in Cases 1 and 4, and on the diaphragmatic surface of the left lung and on the outer surface of the upper lobe of the right lung in Case 2. In all three ases there were petechiae in other parts of the visceral plevira.

The changes in the lungs were thus to the naked eye closely similar to those in Group $\mathbf{E}$, Case 1 . There was, however, more evidence of broncho-pneumonia, especially in Case 2. Thus, there was an area of collapse, perihronchial consolidation, and muco-purulent bronchitis in the lower part of the lower lobe of the right lung in Case 2, and there were areas of collapse in all three iases. In all lungs many bronchioles contained mucus, and in Cases 2 and 4 some containcd muco-pus. In Cases 2 and 4 there was muco-purulent bronchitis and tracheitis. In Group E, Case 1 the microsiope showed two distinct changes in the lungs: (1) a peculiar haemorrhagic vesicular pneumonia, complicated by pulmonary thrombosis and free from bacteria; and (2) a muco-purulent bronchitis in which bacteria were numerous and which was cccasionally associated with resorption collape. The naked-eye appear- ances of the later three cases suggest a combination of similar pneumonia with more advanced broncho-pnemonia.

The bronchial glands were anthracotic and very cedematous; in Case 2 areas that were not anthracotic were engorged and infiltrated.

The spleen in Case 1 weighed 198.5 grams, felt soft, and had a moist cut surface in which the Malpighian bodies and trabeculace appeared swollen and blurred in a pink pulp. In Case 2 it weighed 311.8 grams, felt soft, ancl had a moist cut surface in which a swollen, deep red, soft pulp obscured the Malpighian bodies and trabeculac. In Case 4 it weighed 262.3 grams, was flabby, and lad a cut surface in which an abundant soft, purplish-red pu!p obscured the Malpighian bodies and trabeculac.

Ifuscle.-In Case 2 there were in the right and left rectus abdominis irregular areas in which the muncle was somewhat waxy, very pale, and yellowish-pink. They woro most numerous in the upper and lower ends of the recti, and the largest area measured 2 by 2 by $0.8 \mathrm{~cm}$. Thero were thin layers of blood between these areas and the posterior sheath. Near the upper end of the loft rectus was a ragged tear, $0.5 \mathrm{~cm}$. long. The other abdominal muscles, the pectoral muscles, and the muscles of the right thigh showed no abnormality. In Case 4 there were hacmorrhages into the right and left rectus abdominis; the largest measured 11 by $1 \mathrm{~cm}$. and occupied the lower end of the left rectus and its sheath. There was a group of haemorrhages in an area of $4 \mathrm{~cm}$. diameter in the right and in the left gluteus maximus.

Alimentary Tract.-The stomach in Cases 2 and 4 was congested, and there was in each case an arca of slimit haemorrhage into the mucosa of the bodr. There wa!s slight patchy congestion of the small and large intestino in Cases 2 and 4. In Case 1 the mucose was congestch and covered by prune-juice blood, and there were haemorrhages into the valrulae conniventes, in the jojumum for two and a half feet beginning five feet below the duodenojejunal flexure. In this case the ascending and transverso colons werc distended by gas. The congestion and slight mucosal haenorrhages were probably the result of heart failure. There was no evidence of enteritis. The intestinal lymphoid follicles and the mesenteric glands were not inflamed. The small intestines contained rellow chrme, and the large intestines a little yellow, or olive irresi (Case 2), semi-fluid faeces.

The brains and cords showed congestion and osdema. There were ring-haemorthages in the brain and cord of Case 4, and in the cord of Case 2.

We wish to express our indebtedness to Dr. O. Leytom and Dr. D. Hunter of the London Hospital; and to Drs F Porter Smith, W. J. C. Fenton E. Herga, A. Y. Milne C. W. von Bergen S. J. Ormond, M. Radford, F. Rushworth, M. R. Misiry, B. Hord, G. $C$ Ormond, M. Radford, F. Rushworth, M. R. Mistry, B. Hond, G. C.
Pether, J. G. O'Brien, E. W. Masterman, N. H. Linzec, J. I. Bovd, and R. Clark for their valuable co-operation. We aiso wish to thank Dr. P. N. Panton for the blood counts; Drs. S. P. Bedson and G. T. Western for laboratory investigations, blood cultures, and agglutination tests; Professor H. M. Turnbull for the pathological reports; Colonel A. E. Hamerton of the Zoological Socicly; and the Ministry of Healih.

\section{RFFERENCES}

${ }^{1}$ Ritter, J. : Deut. Arch. f. Klin. Med., 1880, 25, 53.

Ost: Quoted by Leichtenstern.

${ }^{3}$ Wagner, E. : Deut. Arch. f. klin. Med., 1884, 35, 131 ; 1888. 42. 405.

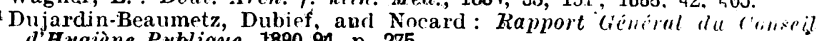
d'Hygiene Publique, 1890-94, p. 275

sicard: Compt. rend. Soc. de Biol., 1897, xlix, 844.

${ }^{6}$ Gilbert and Fournier : Presse Médlicale, 1837 (January), 5. 25.

¿Gilbert and Fournièr : Bull. de l'Acad'. de Méd., 1896, 30, 429.

Gilbcrt and Fournier : Maladies Commanes a l'Homme et aur . Animant, , vol. 4, 295 .

10 icolle, C.: Compt. rent. Soc. te Biol., 1898, 10, 1171.

10 Rome Correspondent: Lancet, April 10th, 1837, 1058.

${ }^{11}$ Leichtenstern: Centralbl. $f$. allgem. Gesund. pffeg., 1899, 18

12 Vickery and Richardson: Med. Neus, 1904, 85, 780 .

${ }^{3}$ MeClintock, A. T. Pleomorphism in Bacterial Protmplasm, 1918 (privately printed).

14 Beddoes, T. P.: Journ. Trop. Mell. and Hygiene, 1914, xvii, 33.

${ }^{15}$ Gulland, G. L. : British Hedical Journal, August 23ro, 1924, p. 308.

${ }_{16}$ Stolkind, E. J. : Med. Press and Circular, 1927 (Janwary-June), p. 259.

17 Thomson, A. P.: Lancet, 1929, ii, 115

18 Thomson, A. P.: Proc. Roy. Soc. Med., 1930, xxiii, 4, 451

19 Radford, M. : British Metical Journal, Pebruary 22nct, 1930, p. 333.

20 Nicolle, C. : Arch. prov. de míd., 1899, 1, 62.

${ }^{21}$ Banti and others: Quoted by Lcichtenstern."

22 Wolff, M. : Virchour's Archiv, 1883, 92, 252.

${ }^{23}$ Ebrrth : Ibid., 1880, 80, 311

2A Perry, H. M.: Brit. Journ. Exp. Path., 1920, i, 131.

Bedson, S. P., Western, G. T., and Levy Simpsen, S. : Lauret, 